Research paper

\title{
Synthesis and biological evaluation of novel pyrazolic chalcone derivatives as novel hepatocellular carcinoma therapeutics
}

\author{
Mohammed M.A. Hawash a, 1 , Deniz Cansen Kahraman ${ }^{\text {b, }}$, Fikriye Eren a, \\ Rengul Cetin Atalay ${ }^{\text {c, ** }}$, Sultan Nacak Baytas ${ }^{\text {a, ** }}$ \\ a Department of Pharmaceutical Chemistry, Faculty of Pharmacy, Gazi University, 06330, Ankara, Turkey \\ ${ }^{\mathrm{b}}$ Department of Molecular Biology and Genetics, Bilkent University, 06800, Ankara, Turkey \\ ${ }^{\mathrm{c}}$ Cancer Systems Biology Laboratory, Graduate School of Informatics, METU, 06800, Ankara, Turkey
}

\section{A R T I C L E I N F O}

\section{Article history}

Received 22 November 2016

Received in revised form

2 February 2017

Accepted 3 February 2017

Available online 10 February 2017

\section{Keywords:}

Hepatocellular carcinoma

Chalcone derivatives

Pyrazoles

Cytotoxic activity

Apoptosis

Cell cycle

Cyclin B1/CDK1 inhibitors

\begin{abstract}
A B S T R A C T
Despite having the second highest mortality associated with cancer, currently Sorafenib is the only FDAapproved chemotherapeutic agent available for liver cancer patients which can only improve survival for few months. In this study, various pyrazolic chalcone analogous compounds were synthesized and evaluated as potential chemotherapeutic agents for the treatment of hepatocellular carcinoma (HCC). Modifying the central pyrazole ring at the $\mathrm{C}(3)$-position with different heteroaryl rings and substituting the $\mathrm{C}(4)$-position of pyrazole with differently substituted chalcone moiety produced fouthy two variant compounds. For all these compounds, cytotoxicity was evaluated using sulforhodamine B assay and real time cell growth tracking, respectively. Based on $50 \%$ inhibitory concentration $\left(\mathrm{IC}_{50}\right)$ values, compounds 39, 42, 49, and 52 were shown to exhibit potent cytotoxic activity against all the cancer cell lines tested and had better cytotoxic activities than the well-known chemotherapeutic drug 5-FU. Therefore, these compounds were chosen to be further evaluated in a panel of HCC cell lines. Flow cytometric analysis of HCC cells treated with compounds 39, 42, 49, and 52 demonstrated that these compounds caused cell cycle arrest at G2/M phase followed by the apoptotic cell death and impaired cell growth as shown by real-time cell growth surveillance. Consistent with these results, western blotting of HCC cells treated with the compounds resulted in molecular changes for cell cycle proteins, where p21 levels were increased independent of p53 and the levels of the key initiators of mitosis Cyclin B1 and CDK1 were shown to decrease upon treatment. In conclusion, chalcone derivatives $\mathbf{4 2}$ and $\mathbf{5 2}$ show potent bioactivities by modulating the expression of cell-cycle related proteins and resulting in cell-cycle arrest in the HCC cell lines tested here, indicating that the compounds can be considered as preclinical candidates.
\end{abstract}

(c) 2017 Elsevier Masson SAS. All rights reserved.

\section{Introduction}

Hepatocellular carcinoma (HCC) is the sixth most common cancer and the second most frequent cause of cancer-related mortality [1]. Each year, around five hundred thousand new cases are diagnosed world-wide and nearly $85 \%$ of all cases are from developing countries. The 5 year survival rate of HCC patients are low and the incidence of HCC continues to rise ( 3 fold increase in 20 years). The etiological factors associated with HCC are chronic

\footnotetext{
* Corresponding author.

** Corresponding author.

E-mail addresses: rengul@metu.edu.tr (R. Cetin Atalay), baytas@gazi.edu.tr (S.N. Baytas).

1 These authors contributed equally.
}

infection by Hepatitis B virus (HBV) and Hepatitis C virus (HCV), aflatoxin exposure, chronic alcohol intake, and obesity [2,3]. Currently, Sorafenib, a multikinase inhibitor, is the only drug approved by FDA for the treatment of HCC which can only prolong patient survival for a short period of time (2-3 months) [4]. Since liver cancer cells display inherent resistance to conventional chemotherapy and radiotherapy, it is critical to develop novel therapeutic drugs against HCC.

Dysregulation of cell cycle control and cell division is highly correlated with cancer development, growth and progression. Liver cancer develops during chronic liver injury which involves immune response along with cytokines and chemokine activation. Hence during chronic liver disease, cycles of hepatocyte cell death and regeneration are induced which engage the activation of cell cycle proteins [5]. Cyclin-dependent kinases (CDKs) are one of the key 
cellular kinases involved in cell cycle regulation in liver [6]. They act together with their cyclin partners to phosphorylate the $\mathrm{Rb}$ protein which helps the release of transcription factors to ensure cell cycle transition. Alterations in the activities of CDKs lead to the transformation of normal cells toward cancerous state [7-12]. Therefore, design and synthesis of therapeutic agents targeting CDKs have been the subject of recent drug discovery research studies and a number of CDK inhibitors have been considered in several clinical trials [13-16]. Hence Palbociclib, which is a selective inhibitor of CDK4 and CDK6, was approved by the FDA to be used in combination with letrozole for the treatment of postmenopausal women with HER2-negative advanced breast cancer [17-20].

Chalcones, 1,3-diaryl-2-propen-1-ones, are naturally occurring intermediates of flavonoid compounds [21]. Chalcones have shown broad range of biological activities such as antioxidant, antibacterial, antifungal, anti-HIV, antileishmanial, antifilarial, antimalarial, anti-inflammatory, and anticancer properties [22,23]. It has been determined that many chalcone derivatives exhibit cytotoxic activity in various cancer cell lines through different molecular mechanisms [24,25].

Pyrazoles with their distinctive scaffold possess wide range of anticancer bioactivities [26-31]. Though more widely known for their use in analgesic, antipyretic and anti-inflammatory actions, pyrazoles can also have antileukemic [32,33], antitumor [34,35] and anti-proliferative [36]. Although the pyrazole skeleton is an important building block in mediating its biological effects, the type of peripheral substituents are crucial for their selectivity toward their targets. Studies concerning structure-activity relationships have shown that the cytotoxic potency of the compounds has been highly dependent on the substitution types and patterns on the aryl ring. Thus, 3,4-disubstituted pyrazole analogues, and 3-<smiles>CNC(=O)c1cc(Oc2ccc(NC(=O)Nc3ccc(Cl)c(C(F)(F)F)c3)cc2)ccn1</smiles>

Sorafenib<smiles>CCC(CO)Nc1nc(NCc2ccccc2)c2ncn(C(C)C)c2n1</smiles>

Seliciclib (imidazol-2-yl)-4-[2-(pyridin-3-yl)-vinyl]-pyrazoles (1), have been reported as cyclin-dependent kinase (CDK) inhibitors and have been shown to inhibit in vitro cellular proliferation in various human cancer cells [37]. In another study, Huang et al. showed that $N$ ((1,3-diphenyl-1H-pyrazol-4-yl)methyl)aniline derivative 2 [38] had inhibitory activity on MCF-7 and B16-F10 cell lines with $\mathrm{IC}_{50}$ values of 1.88 and $2.12 \mu \mathrm{M}$, respectively. Compound 2 inhibits the CDK2/cyclin E holoenzyme activities with $\mathrm{IC}_{50}$ of $0.98 \mu \mathrm{M}$ (Fig. 1). Recently, (N-((1-benzyl-1H-1,2,3-triazol-4-yl)methyl)-1,3diphenyl- $1 H$-pyrazole-4-carboxamide derivatives were reported as CDK1/Cdc2 inhibitors [39].

In our previous studies, we reported 1,3-diarylpyrazole derivatives containing thiophene and pyridine heterocycles as significant antiproliferative agents against MCF7, MDA-MB-231, HeLa, Raji and HL60 human cancer cell lines (3 in Fig. 1) [40,41]. Therefore considering the limited availability of targeted therapies in liver cancer, in this study, the cytotoxicities of pyrazolic chalcone derivatives are investigated in order to identify the potential bioactivities as drug candidates in treatment of HCC. Here we report the synthesis and the biological activities of a new series of 1,3,4trisubstitutedpyrazoles $\mathbf{1 2}-\mathbf{5 3}$ in which; $i$ ) a heteroaryl moiety (3-thienyl, 3-(benzo[d][1,3]dioxol-5-yl, 3-pyridyl, 4-pyridyl) is attached to the central pyrazole ring at position 3 ; ii) phenyl is attached to the pyrazole ring at position 1 and iii) chalcone moiety is attached to the central pyrazole ring at position 4 .

\section{Results and discussion}

\subsection{Chemistry}

The 1,3-diarylpyrazole chalcone derivatives (12-53) were<smiles>CC(=O)C1C(=O)N(C2CCCC2)c2nc(Nc3ccc(N4CCNCC4)cn3)ncc2C1C</smiles>

Pablociclib<smiles>O=C(NC1CCNCC1)c1n[nH]cc1NC(=O)c1c(Cl)cccc1Cl</smiles>

AT7519

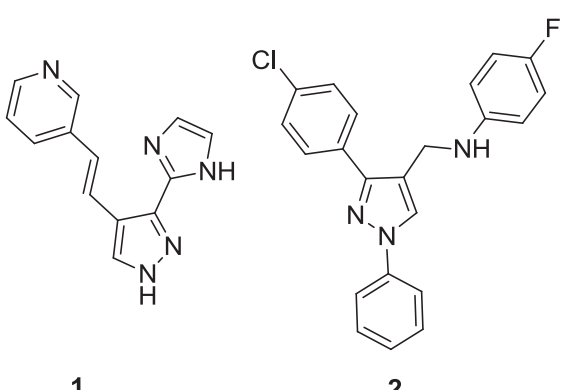

1

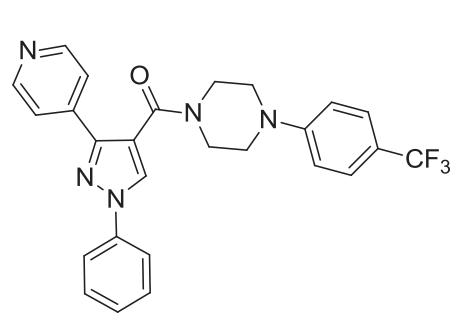

3

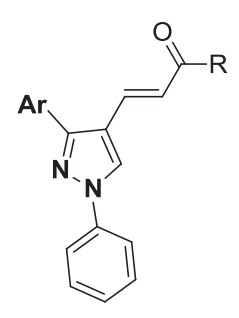

$12-53$

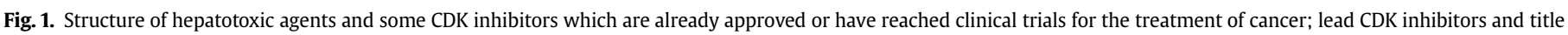
compounds. 
synthesized as outlined in Scheme 1. The hydrazone derivatives 4-7 were generated by condensing appropriate methyl ketone and phenylhydrazine in the presence of acetic acid in refluxing ethanol. The IR spectra of hydrazone 4-7 showed disappearance of the carbonyl peak that belonged to acetyl group of methyl ketone derivatives. This hydrazone derivative was then reacted with $\mathrm{POCl}_{3}$ and DMF resulting in 1,3-diaryl pyrazoles 8-11 with aldehyde group at 4 position. 1,3-Diarylpyrazole chalcone analogs 12-53 were prepared by condensation of 1-phenyl-3-heteroaryl-1H-pyrazole-4-carboxaldehyde derivatives 8-11 and corresponding methyl ketones in ethanol solution, applying $40 \%$ aqueous $\mathrm{NaOH}$ as a catalyst.

All compounds were purified either by automated flash chromatography or recrystallization; or automated flash chromatography then recrystallization and checked for purity by elemental analysis or UPLC (purity was $>97 \%$ ) before being tested in biological assays. The structures of these compounds were confirmed by high-resolution mass spectrometry (HRMS), IR, ${ }^{13} \mathrm{C}$ NMR and ${ }^{1} \mathrm{H}$ NMR spectral data. Elemental analysis results were also provided for eighteen of the title compounds.

\subsection{Biological evaluations}

\subsubsection{Cytotoxicities of the pyrazolic chalcone derivatives in liver cancer cells}

Pyrazolic chalcone derivatives (12-53) were initially screened against Hepatocellular (Huh7), breast (MCF7) and colon carcinoma (HCT116) cells. Bioactivities of each compound were evaluated by sulforhodamine B (SRB) assay. The $\mathrm{IC}_{50}$ values after $72 \mathrm{~h}$ of treatment with each molecule were calculated in comparison with the well known chemotherapeutic agents such as, nucleobase analogue 5-fluorouracil (5-FU) and nucleoside analogue cladribine. IC $_{50}$ values were in between 0.3 and $29 \mu \mathrm{M}$ as shown in Table 1 .

In general, compounds having thenyl moiety at position 3 on the pyrazole ring (12-19) displayed great antiproliferative potency on all cancer cell lines with the exception of the benzo[d][1,3]dioxol-5yl chalcone derivative 19. Compounds having methoxy substituent at positions 3 and 4 or at 2 and 5 on the phenyl chalconic moiety of the molecules $(\mathbf{1 6}, \mathbf{1 7})$ showed $\mathrm{IC}_{50}$ values of $0.4-3.4 \mu \mathrm{M}$ in Huh7, MCF7 and HCT116 cell lines.

Replacing the thenyl moiety (12-19) with benzo[d][1,3]dioxol5 -yl ring (20-31) resulted in a significant decrease in the cytotoxic activity of the compounds which bears methoxy groups on the phenyl chalconic moiety especially against Huh7 $(6.1-19.0 \mu \mathrm{M})$ and MCF7 (5.8-14.5 $\mu \mathrm{M})$. Compounds having benzo[d][1,3]dioxol-5-yl moiety at position 3 on the pyrazole ring and heterocyclic rings such as 3-thenyl, 3-/2-pyridyl at the chalconic part (27-29) showed notable antiproliferative activity against Huh7 (3.2-3.4 $\mu \mathrm{M})$, MCF7
$(2.2-4.9 \mu \mathrm{M})$ and HCT116 $(3.8-8.9 \mu \mathrm{M})$ cell lines. Derivatives 30 (having benzo[d] [1,3]dioxol-5-yl moiety at both on the pyrazole and chalcone part) and 31 (bearing benzo[d][1,3]dioxol-5-yl moiety at position 3 on the pyrazole and 3-pyrolyl moiety at chalcone part) had weak activity for all cell lines used in this study $(9.2-27.2 \mu \mathrm{M})$.

The 3-/4-pyridyl derivatives at 3 position of pyrazole ring (32-53) displayed very significant antiproliferative activity on all cancer cell lines ( $\mathrm{IC}_{50}$ values of below $7 \mu \mathrm{M}$ ) with the exception of compound 46 which bears 3-pyrolyl moiety at chalcone part. Introduction of heterocylic rings at chalcone part as in compounds $\mathbf{3 3}, \mathbf{3 4}, \mathbf{3 5}, \mathbf{3 6}, 46 \mathrm{did}$ not result in any advantage toward the activity of the compounds. In 3-pyridyl series, regarding the effect of substitution on the phenyl ring ( $R$ ) at chalcone side, the 2,4,6trimethoxy derivative $\mathbf{3 9}$ has remarkable cytotoxic activity against all tested human cancer cells, especially to Huh7 (Table 1). Compound 42, the 2,5-dimethoxy derivative were also showed significant activity against all test cell lines ( IC $_{50}$ values of $1,3 \mu \mathrm{M}$ Huh7; $1.5 \mu \mathrm{M}$ MCF7; $1 \mu \mathrm{M}$ HCT116). Their analogs in 4-pyridyl series, compounds $\mathbf{4 9}$ and $\mathbf{5 2}$ were also very active, with $\mathrm{IC}_{50}$ values in the range of $0.6-2.6 \mu \mathrm{M}$ against all tested cell lines following $72 \mathrm{~h}$ of treatment. When we compared the $\mathrm{IC}_{50}$ values of these compounds to well-known chemotherapeutic drugs, we observed that they were lower than 5-FU and comparable to that of cladribine. Therefore, the compounds which displayed significant cytotoxic effects $(39,42,49,52)$ were chosen to be further evaluated in a panel of HCC cell lines composed of Huh7, HepG2, Mahlavu and SNU-475 cells, MCF12A, normal human breast epithelial cells and MRC5, human fetal lung fibroblast cells. Our results showed that pyrazolic chalcone derivatives were cytotoxic to HCC cells, however they were less cytotoxic to MCF12A and MRC-5 cells. (Table 2). Additionally, compound $\mathbf{4 9}$ had no cytotoxicity on MRC5 cells.

Recent studies have shown that some chalcone derivatives inhibit cell growth of several human cancer cell lines as tubulin binding and depolymerizing agents [34]. The chalcone analogs of some natural products such as combretastatin have been synthesized and developed by Ducki et al. [42]. These chalcone analogs show potent inhibition of tubulin assembly and possess promising anticancer activity, and are currently under preclinical evaluation $[43,44]$. Based on this information, we analyzed the effect of compounds $\mathbf{1 2}-\mathbf{5 3}$ on tubulin polymerization, however no inhibitory effect on tubulin polymerization was observed (data not shown).

\subsubsection{Real-time cellular response of hepatocellular carcinoma cells with 39, 42, 49 and 52 treatment}

Time-dependent cytotoxic activities of pyrazole chalcone derivatives were performed with real time cell electronic sensing (RTCES) on Huh7, HepG2, Mahlavu and SNU-475 cells. It was shown that all compounds reduced the growth rate of cells compared to<smiles>[R]C(=O)/C=C/c1cn(-c2ccccc2)nc1[R16]</smiles>

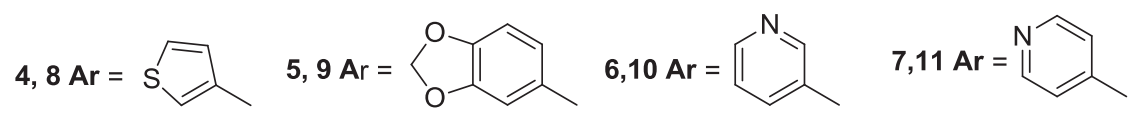

Scheme 1. Synthesis of 1,3-diarylpyrazole chalcone derivatives. Reagents and conditions: i.) Phenyl hydrazine, acetic acid, ethanol, $2 \mathrm{~h}$ reflux. ii.) Dimethyl formamide, POCl $3,50{ }^{\circ} \mathrm{C}$, $4 \mathrm{~h}$ iii.) methyl ketone derivatives, $\mathrm{NaOH}$, EtOH. 
Table 1

Cytotoxicity of compounds $\mathbf{1 2 - 5 3}$ and nucleoside analogs 5-FU and cladribine assessed in different human cancer cells.

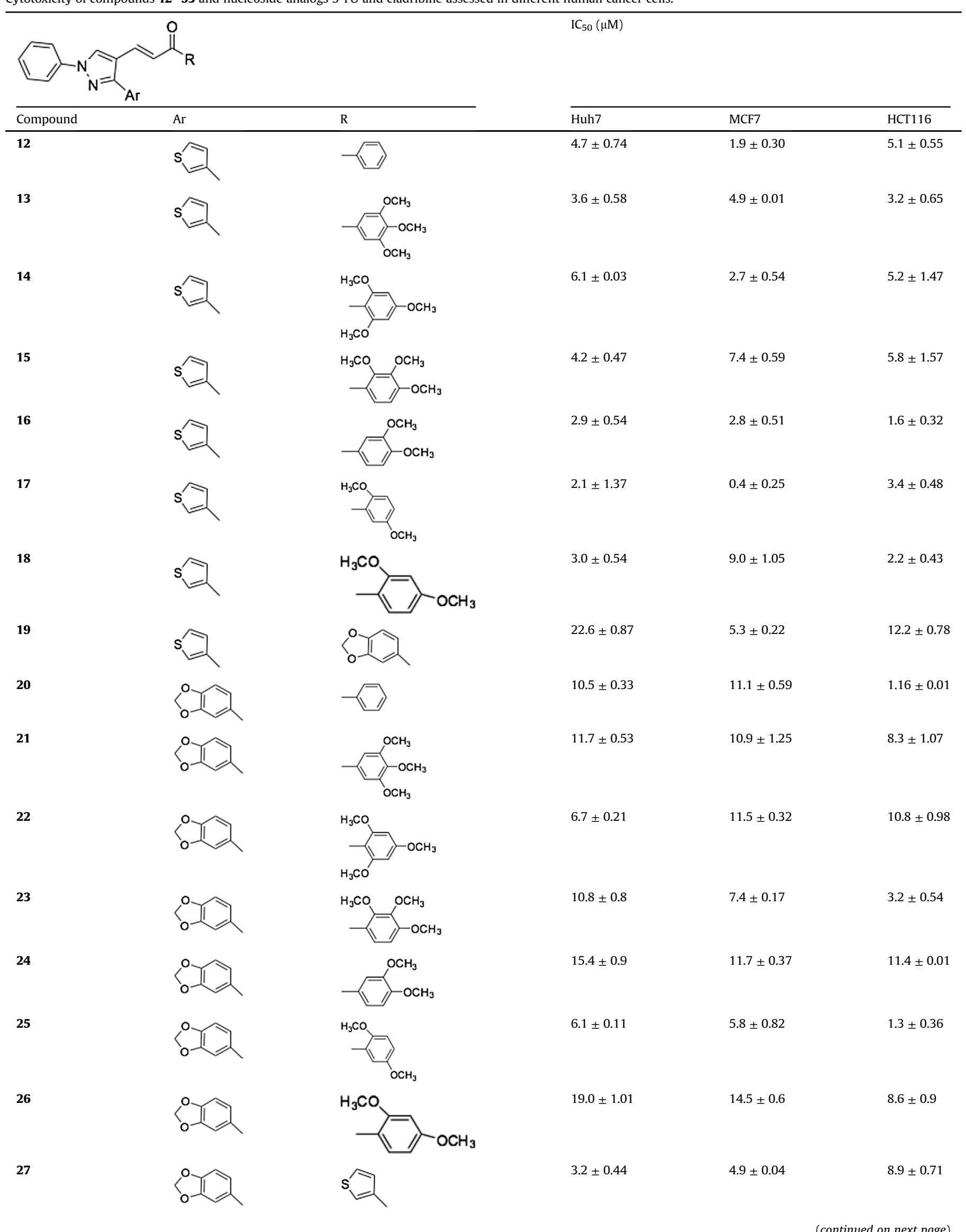


Table 1 (continued)<smiles>[R]C(=O)/C=C/c1cn(-c2ccccc2)nc1[Al]</smiles>

$\mathrm{IC}_{50}(\mu \mathrm{M})$

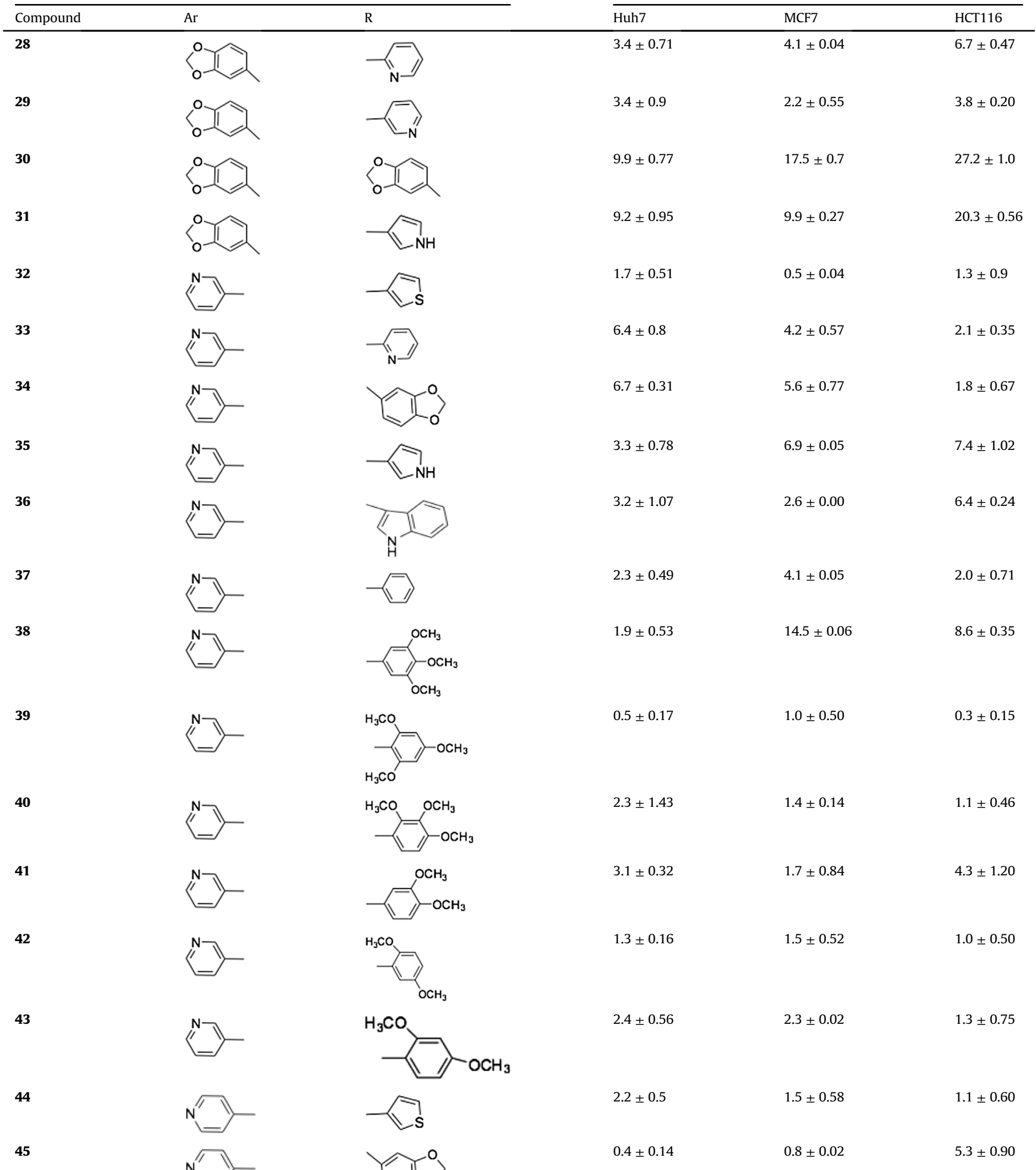




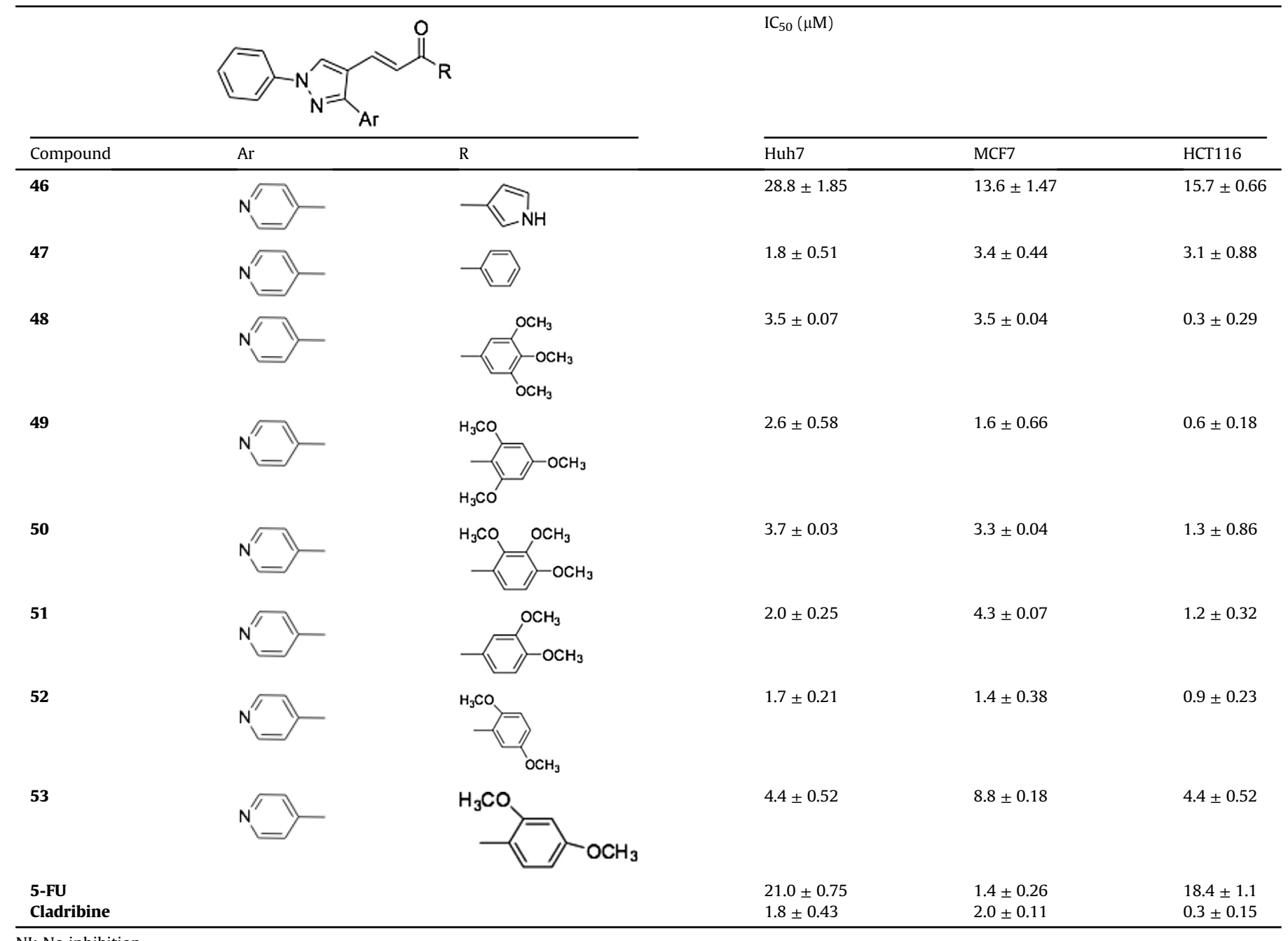

Table 2

$\mathrm{IC}_{50}$ values of compounds 39, 42, 49 and 52 for HCC cell lines (Huh7, HepG2, Mahlavu and SNU-475) and in epithelial cells (MCF12A and MRC-5).

\begin{tabular}{lllllll}
\hline \multirow{2}{*}{ Compound } & \multicolumn{5}{l}{$\mathrm{IC}_{50}$ Values $(\mu \mathrm{M})$} \\
\cline { 2 - 7 } & Huh7 & HepG2 & Mahlavu & SNU-475 & MCF12A & MRC-5 \\
\hline $\mathbf{3 9}$ & $\mathbf{0 . 5} \pm 0.2$ & $\mathbf{1 . 4} \pm 0.2$ & $\mathbf{1 . 1} \pm 0.2$ & $\mathbf{0 . 8} \pm 0.1$ & $\mathbf{1 . 2} \pm 0.5$ & $\mathbf{1 . 3} \pm 0.6$ \\
$\mathbf{4 2}$ & $\mathbf{1 . 3} \pm 0.2$ & $\mathbf{3 . 4} \pm 0.8$ & $\mathbf{2 . 0} \pm 0.3$ & $\mathbf{1 . 9} \pm 0.1$ & $\mathbf{2 . 4} \pm 0.8$ & $\mathbf{2 . 7} \pm 0.9$ \\
$\mathbf{4 9}$ & $\mathbf{2 . 6} \pm 0.6$ & $\mathbf{1 . 7} \pm 0.1$ & $\mathbf{1 . 1} \pm 0.1$ & $\mathbf{1 . 4} \pm 0.3$ & $\mathbf{8 . 2} \pm 0.6$ & $\mathbf{N I}$ \\
$\mathbf{5 2}$ & $\mathbf{1 . 7} \pm 0.9$ & $\mathbf{4 . 8} \pm 0.3$ & $\mathbf{1 . 6} \pm 0.2$ & $\mathbf{2 . 0} \pm 0.3$ & $\mathbf{3 . 0} \pm 0.6$ & $\mathbf{3 . 1} \pm 0.9$ \\
\hline
\end{tabular}

NI: No inhibition in cell growth.

the DMSO control (Fig. 2). This real-time growth pattern suggested that the growth inhibition was due to cell cycle arrest, where the cells were neither proliferating nor dying, whereas the cells treated with DMSO continued to proliferate until they reach confluence [45].

\subsubsection{Characterization of cell death mechanism induced by pyrazolic chalcone derivatives}

HepG2 and SNU475 cells were treated with the compounds for $48 \mathrm{~h}$. In order to determine the death mechanism induced by pyrazolic chalcone derivatives, fluorescent microscopy using Annexin V staining was employed. Compared to DMSO controls, cells treated with all four of the chosen compounds were detached from the surface (Suppl. Fig. 5) and cells with condensed nuclei were positive for Annexin V staining, which indicates apoptotic cell death (Fig. 3a). After $24 \mathrm{~h}$ of treatment, PARP cleavage was observed in poorly-differentiated SNU475 cells by western blot analysis compared to well-differentiated HepG2 cells (Fig. 3b) [46].

\subsubsection{Induction of G2/M cell cycle arrest by the pyrazolic chalcone derivatives}

Since the pattern of cell growth observed from the real-time cell analysis suggested the induction of cell cycle arrest flow cytometry analysis using propidium iodide (PI) staining of DNA was then performed. Following 48 hrs of treatment entry to G2/M phase was observed to be increased, which subsequently caused entry into sub-G1 phase at 72 h, especially with compounds $\mathbf{3 9}, \mathbf{4 2}$ and $\mathbf{5 2}$ (Fig. 4). Altogether, our results indicate that pyrazolic chalcone derivatives induce cell cycle arrest at the G2/M phase which was followed by apoptotic cell death in hepatocellular carcinoma cell lines.

\subsubsection{Analysis of targeted cellular pathways}

Cell cycle-related proteins more specifically those that are involved in the G2/M phase were analyzed by western blotting (Fig. 5). CyclinB1 and CDK1 complex was previously shown to be critical for the progression of cells in and out of $\mathrm{M}$ phase of the cell 

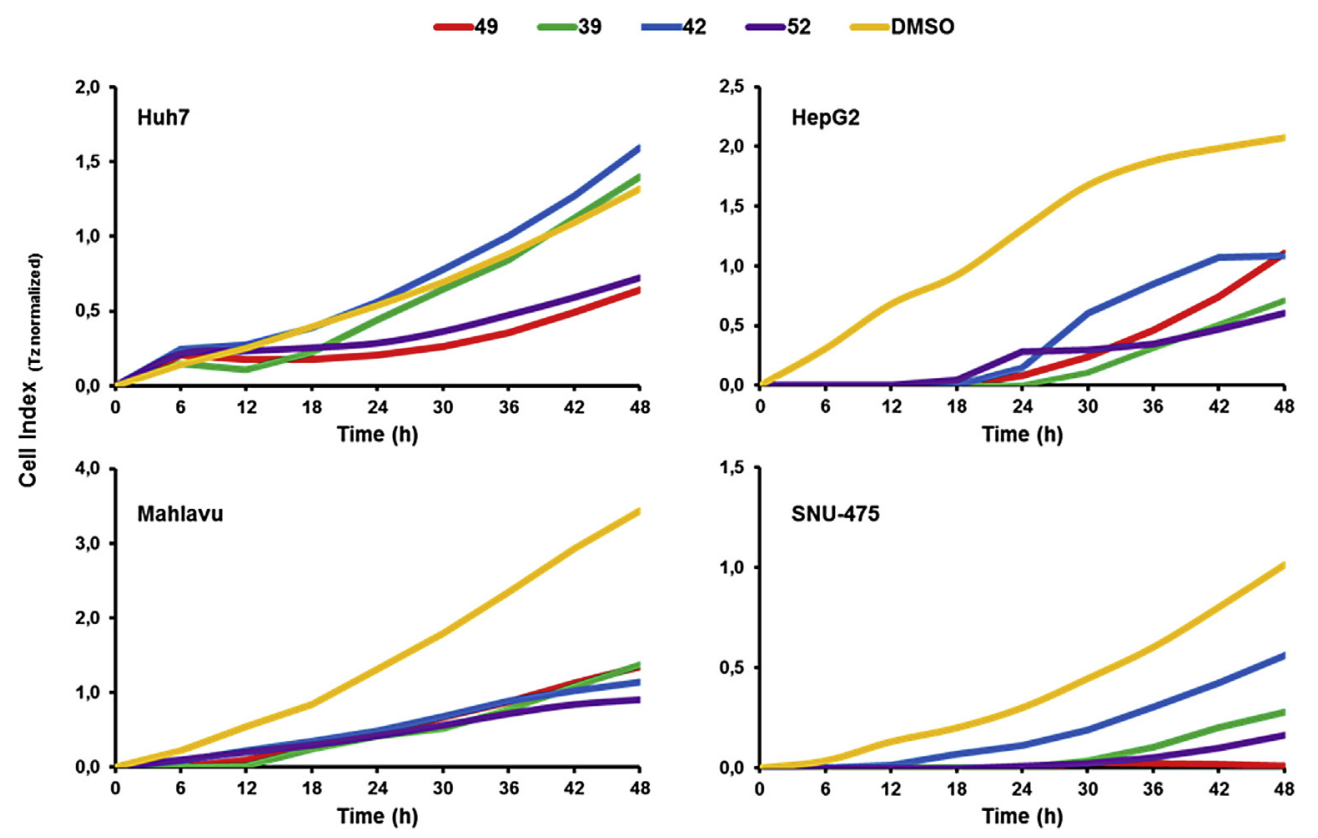

Fig. 2. RT-CES analysis of HCC cell lines treated with compounds $\mathbf{3 9}, \mathbf{4 2}, \mathbf{4 9}$ and $\mathbf{5 2}$ and with DMSO control $(0.1 \%)$ at $\mathrm{IC}_{100}$ concentrations for 48 h.

A

DMSO

39

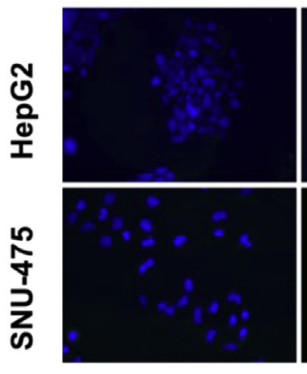

\section{B}

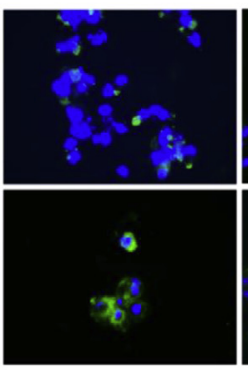

42
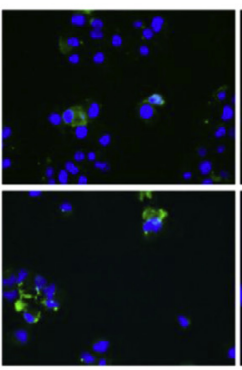

HepG2
49
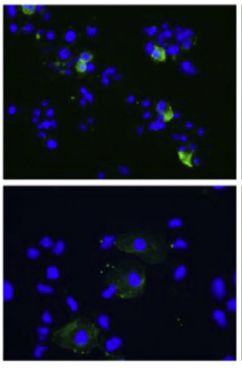

52

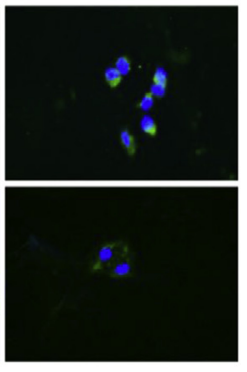

SNU-475
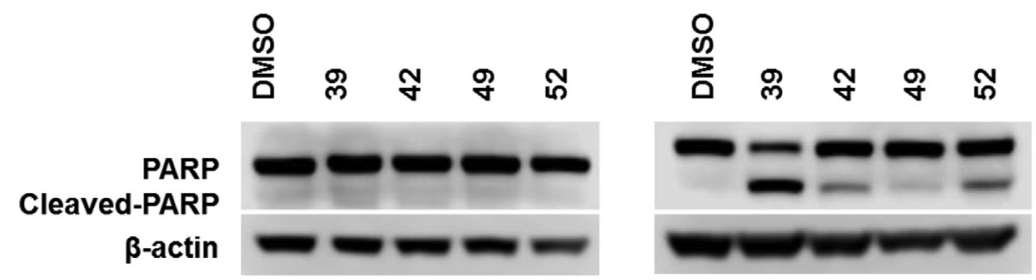

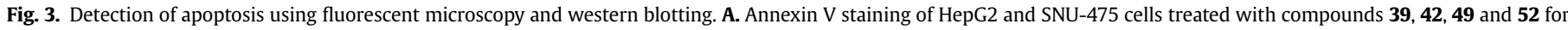

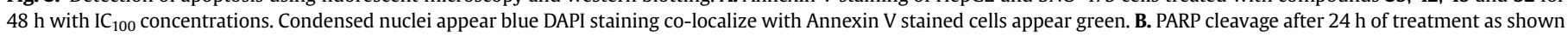
by western blot analysis. (For interpretation of the references to colour in this figure legend, the reader is referred to the web version of this article.)

cycle. Upon treatment with pyrazolic chalcone derivatives 42 and $\mathbf{5 2}$, levels of CDK1 were shown to decrease by half in HepG2 cells, whereas a minor change was observed for SNU475 cells. PhosphoCyclin B1 levels were shown to decrease by half in HepG2 cells, although there was a slight reduction in Cyclin B1 protein levels. It is well known that phosphorylation of Ser147 is necessary for the nuclear translocation of Cyclin B1 during prophase. Therefore, our results are indicate that pyrazole chalcone derivatives could be involved in a mechanism inducing inhibition of Cyclin B1 phosphorylation, which results in a decreased amount of active Cyclin
B1, translocating into the nuclei. In addition to this, levels of p21, known to inhibit the activation of CyclinB1/CDK1 complex, were shown to increase by $5-6$ fold in HepG 2 cells and nearly 2 fold in SNU475 cells upon treatment with compounds $\mathbf{4 2}$ and $\mathbf{5 2}$. It was further explored that this change in p21 levels were independent of p53 levels. The phospho-Rb levels were also found to be decreased, further impairing the cell cycle machinery, which could be the implication of secondary effects of pyrazolic chalcone derivatives on cell cycle. 
HepG2
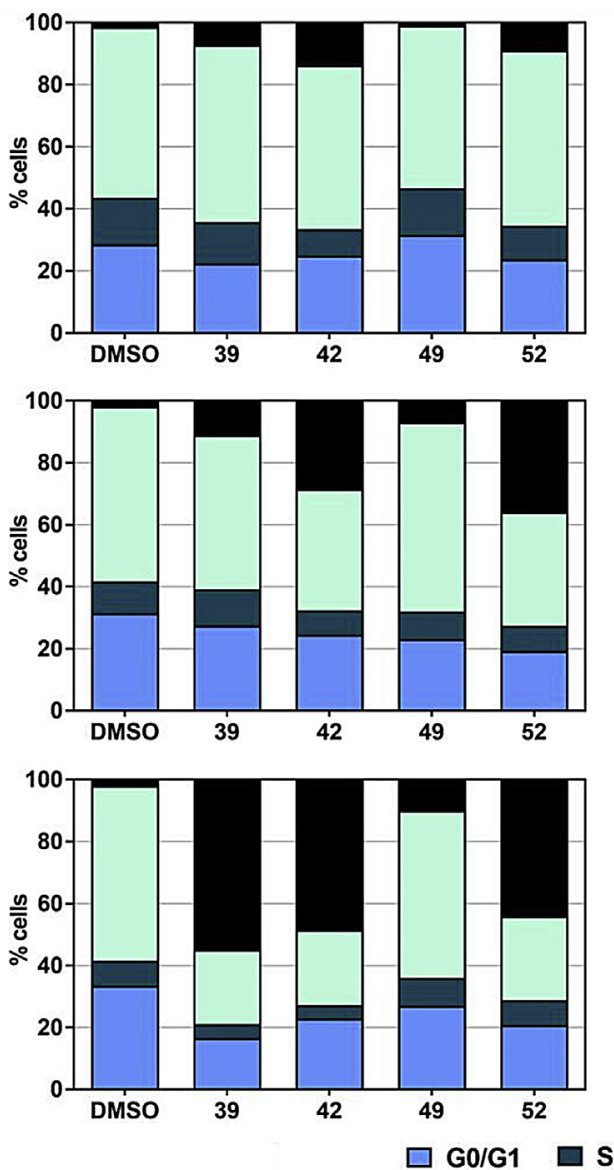

SNU-475
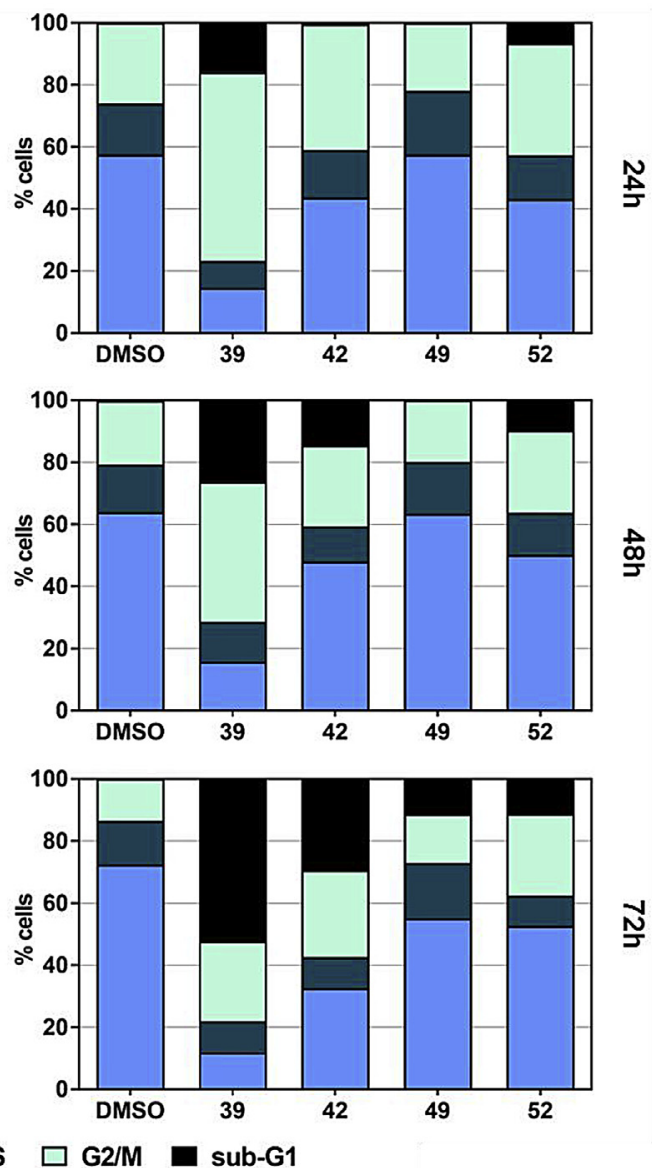

Fig. 4. Cell cycle analysis of HepG2 and SNU475 cells after treatment with compounds 39, 42,49 and 52 and DMSO controls following 24 h, 48 h, and 72 h of treatment.

\section{Conclusion}

In this study, we synthesized a series of pyrazolic chalcone derivatives and evaluated their antiproliferative activities against human cancer cell lines in comparison with clinically used chemotherapeutics such as 5-FU and Cladribine. The preliminary structure bioactivity relations in these compounds have been established and discussed in results section in detail. The central pyrazole ring was modified at the $\mathrm{C}(3)$-position with different heteroaryl rings and substituted at the $C(4)$-position with differently substituted chalcone moiety. Based on preliminary screenings the benzo[d][1,3]dioxol-5-yl ring (20-31) was not tolerated and resulted in mostly inactive or weak inhibitory compounds. Modifications of C(3)-position of central pyrazole ring with 3-/4-pyridyl moiety improved the bioactivity bearing more potent cytotoxic compounds. Therefore compounds 39, 42, 49, and 52 were the most effective derivatives which displayed antiproliferative activity with $\mathrm{IC}_{50}$ values smaller than $5 \mu \mathrm{M}$ against HCC cells used here. Moreover, these compounds were less active on transformed and normal cells (MCF12A and MRC-5). By further investigating their molecular effectors, we showed that compounds $\mathbf{4 2}$ and 52 caused cell cycle arrest at the G2/M phase and induced apoptotic cell death (as summarized in Fig. 6). Moreover, decrease in levels of phosphocyclin B1 at the Ser147 residue upon treatment is worth exploring, since it could provide further information about the mechanism of action of the compounds on cancer cells. Future studies can evaluate the detailed cellular networks that are affected by the use of high throughput genomic screening methods such as transcriptome analysis with next-generation sequencing in the presence of selected compounds. This may allow to identify molecular targets involved in cell cycle for eventual drug design and development in cancer.

\section{Experimental}

\subsection{Chemistry}

Melting points were determined with an SMP-II Digital Melting Point Apparatus and are uncorrected (Schorpp Geaetetechnik, Germany). IR spectra were obtained using a Perkin Elmer Spectrum 400 FTIR/FTNIR spectrometer equipped with a Universal ATR Sampling Accessory. ${ }^{1} \mathrm{H}$ NMR and ${ }^{13} \mathrm{C}$ NMR spectra were recorded in $\mathrm{CDCl}_{3}$ or DMSO- $d_{6}$ on a Varian Mercury $400 \mathrm{MHz}$ High Performance Digital FT-NMR spectrometer at the NMR facility of the Faculty of Pharmacy, Ankara University or on a Varian Mercury $300 \mathrm{MHz}$ FTNMR spectrometer at the NMR facility of FARGEM (Pharmaceutical Research and Development Center) Inc. using tetramethylsilane as the internal standard. All chemical shifts were recorded as $\delta(\mathrm{ppm})$. High resolution mass spectra data (HRMS) were collected using a Waters LCT Premier XE Mass Spectrometer (high sensitivity orthogonal acceleration time-of-flight instrument) using ESI $(+)$ method. The instrument was coupled to an AQUITY Ultra Performance Liquid Chromatography system (Waters Corporation, Milford, MA, USA). Elemental analyses were performed with a LECO- 

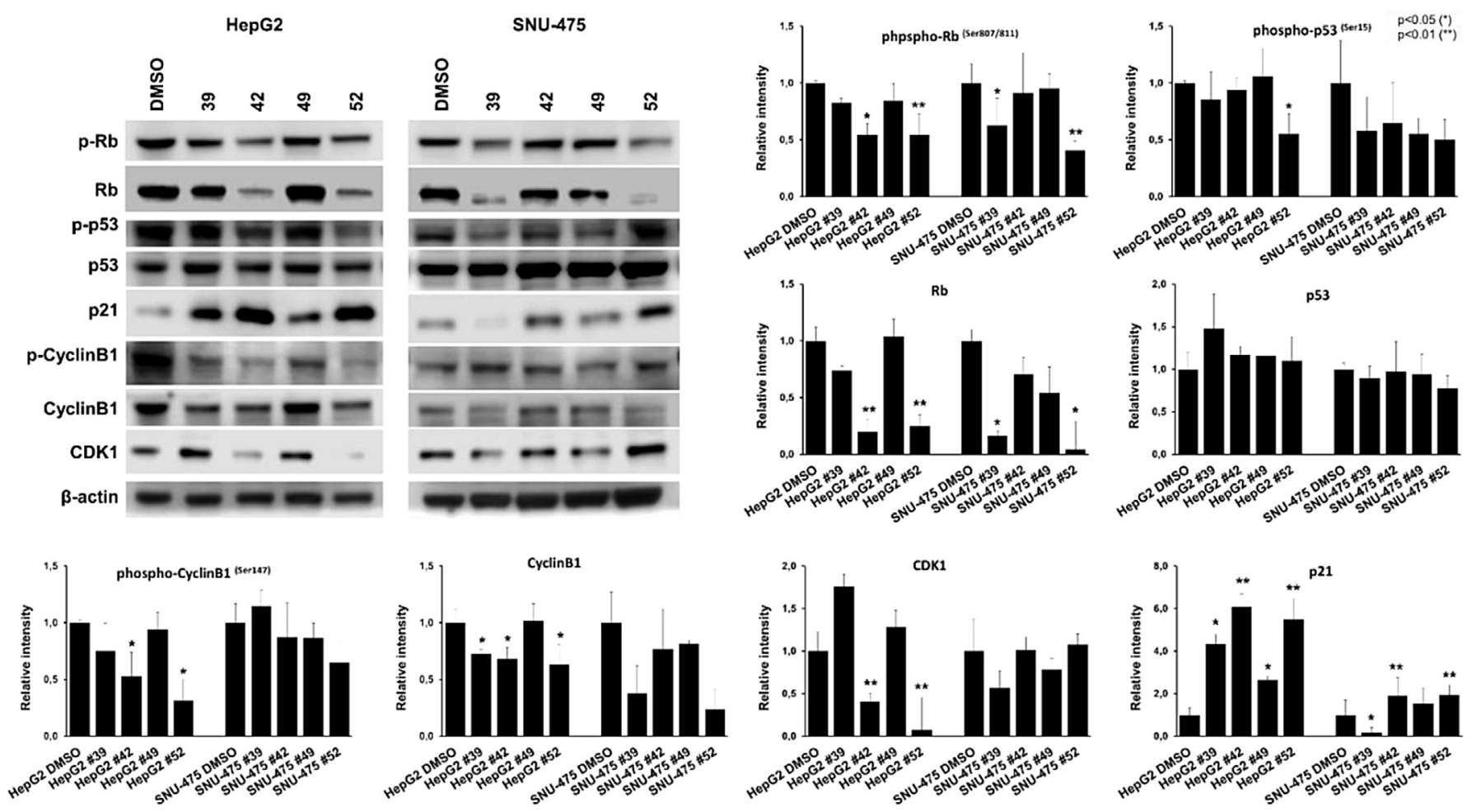

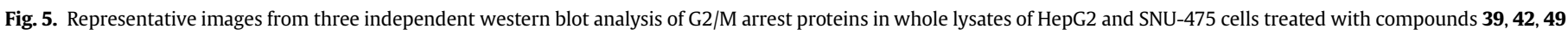
and 52 in $\mathrm{IC}_{100}$ concentrations for $24 \mathrm{~h}$. Graphs demonstrate comparative analysis of protein levels in the presence of compounds normalized to DMSO controls.

932 (C, H, N, S-Elemental Analyzer) at the Faculty of Pharmacy, Ankara University. Flash chromatography was performed with a Combiflash $^{\circledR} \mathrm{Rf}$ automated flash chromatography system with RediSep columns (Teledyne-Isco, Lincoln, NE, USA) using DCM$\mathrm{MeOH}$, hexane-EtOAc or MeOH-EtOAc solvent gradients.

\subsubsection{General procedure for 1,3-diarylpyrazole chalcone synthesis}

To a stirred solution of 1,3-diaryl-1H-pyrazole-4carboxaldehyde (1 $\mathrm{mmol})$ and corresponding methyl ketone $(1.05 \mathrm{mmol})$ in ethanol $(5 \mathrm{ml})$, an aqueous solution of $40 \% \mathrm{NaOH}$ $\left(2 \mathrm{ml}\right.$ ) was added. The resulting solution was heated to $60^{\circ} \mathrm{C}$ for $4 \mathrm{~h}$ and then allowed to stand overnight at room temperature with continuous stirring. The reaction mixture was poured into water and precipitate was collected by filtration, washed with 50\% ethanol, dried, and purified by flash chromatography or recrystallization.

4.1.2. (E)-1-phenyl-3-(1-phenyl-3-(thiophen-3-yl)-1H-pyrazol-4yl)prop-2-en-1-one (CAS No: 303773-77-5) (12)

Purified by column flash chromatography $(0 \% \rightarrow 50 \%$ ethyl acetate in hexane). Yield $76 \%, \mathrm{mp} 138-139^{\circ} \mathrm{C}$; IR (FTIR/FTNIR-ATR): $1657 \mathrm{~cm}^{-1}(\mathrm{C}=\mathrm{O}) .{ }^{1} \mathrm{H}$ NMR $\left(\mathrm{CDCl}_{3}, 300 \mathrm{MHz}\right) \delta: 8.27(1 \mathrm{H}, \mathrm{s})$, $7.94-7.93(2 \mathrm{H}, \mathrm{m}), 7.90(1 \mathrm{H}, \mathrm{d}, J=15.6 \mathrm{~Hz}), 7.71(2 \mathrm{H}, \mathrm{d}, J=9.9 \mathrm{~Hz})$, 7.59-7.58 (1H, m), 7.54-7.37 (7H, m), $7.33(1 \mathrm{H}, \mathrm{d}, J=15.9 \mathrm{~Hz}), 7.27$ $(1 \mathrm{H}, \mathrm{d}, J=7.5 \mathrm{~Hz}) .{ }^{13} \mathrm{C}$ NMR (DMSO- $\left.d_{6}, 400 \mathrm{MHz}\right) \delta: 188.68,148.72$, 138.89, 137.67, 134.08, 133.01, 132.64, 129.66, 128.77, 128.57, 128.19, $127.51,127.23,127.10,124.69,121.39,118.60,117.89$. HRMS $(\mathrm{m} / \mathrm{z})$ : $[\mathrm{M}+\mathrm{H}]^{+}$calcd. for $\mathrm{C}_{22} \mathrm{H}_{17} \mathrm{~N}_{2} \mathrm{OS} 357.1062$, found 357.1064.

\subsection{3. (E)-3-(1-phenyl-3-(thiophen-3-yl)-1H-pyrazol-4-yl)-1-}

(3,4,5-trimethoxyphenyl)prop-2-en-1-one (13)

Purified by column flash chromatography $(0 \% \rightarrow 50 \%$ ethyl acetate in hexane). Yield $21 \%, \mathrm{mp} 167-168^{\circ} \mathrm{C}$; IR (FTIR/FTNIR-ATR):
$1651 \mathrm{~cm}^{-1}(\mathrm{C}=\mathrm{O}) .{ }^{1} \mathrm{H}$ NMR $\left(\mathrm{CDCl}_{3}, 300 \mathrm{MHz}\right) \delta: 8.25(1 \mathrm{H}, \mathrm{s}), 7.89$ $(1 \mathrm{H}, \mathrm{d}, J=15.6 \mathrm{~Hz}), 7.71(2 \mathrm{H}, \mathrm{d}, J=8.7 \mathrm{~Hz}), 7.60-7.58(1 \mathrm{H}, \mathrm{m})$, $7.46-7.38(4 \mathrm{H}, \mathrm{m}), 7.31(1 \mathrm{H}, \mathrm{s}), 7.25(1 \mathrm{H}, \mathrm{d}, J=15.6 \mathrm{~Hz}), 7.19(2 \mathrm{H}, \mathrm{s})$, $3.86(9 \mathrm{H}, \mathrm{s}) .{ }^{13} \mathrm{C}$ NMR (DMSO- $\left.d_{6}, 400 \mathrm{MHz}\right) \delta: 187.46,152.91,148.68$, 141.97, 138.89, 133.89, 133.06, 132.72, 129.70, 128.72, 127.57, 127.27, $127.17,124.77,121.26,118.77,117.89,106.01,60.21,56.23$. HRMS $(m /$ $z$ ): $[\mathrm{M}+\mathrm{H}]^{+}$calcd. for $\mathrm{C}_{25} \mathrm{H}_{23} \mathrm{~N}_{2} \mathrm{O}_{4} \mathrm{~S} 447.1379$, found 447.1384 .

4.1.4. (E)-3-(1-phenyl-3-(thiophen-3-yl)-1H-pyrazol-4-yl)-1(2,4,6-trimethoxyphenyl)prop-2-en-1-one (14)

Purified by column flash chromatography $(0 \% \rightarrow 50 \%$ ethyl acetate in hexane). Yield $81 \%, \mathrm{mp} 162.5-163.5{ }^{\circ} \mathrm{C}$; IR (FTIR/FTNIRATR): $1626 \mathrm{~cm}^{-1}(\mathrm{C}=0) .{ }^{1} \mathrm{H}$ NMR $\left(\mathrm{CDCl}_{3}, 300 \mathrm{MHz}\right) \delta: 8.14(1 \mathrm{H}, \mathrm{s})$, $7.67(2 \mathrm{H}, \mathrm{d}, J=7.8 \mathrm{~Hz}), 7.48-7.26(6 \mathrm{H}, \mathrm{m}), 7.19(1 \mathrm{H}, \mathrm{d}, J=5.1 \mathrm{~Hz})$, $6.73(1 \mathrm{H}, \mathrm{d}, J=16.2 \mathrm{~Hz}), 6.09(2 \mathrm{H}, \mathrm{s}), 3.78(3 \mathrm{H}, \mathrm{s}), 3.72(6 \mathrm{H}, \mathrm{s}) .{ }^{13} \mathrm{C}$ NMR (DMSO- $\left.d_{6}, 400 \mathrm{MHz}\right) \delta$ : 193.13, 161.89, 157.85, 148.11, 138.89, 134.47, 132.70, 129.61, 128.72, 128.31, 127.28, 127.16, 127.02, 123.99, 118.62, 117.21, 110.80, 90.91, 55.77, 55.47. HRMS $(m / z):[M+H]^{+}$ calcd. for $\mathrm{C}_{25} \mathrm{H}_{23} \mathrm{~N}_{2} \mathrm{O}_{4} \mathrm{~S} 447.1379$, found 447.1360 .

4.1.5. (E)-3-(1-phenyl-3-(thiophen-3-yl)-1H-pyrazol-4-yl)-1(2,3,4-trimethoxyphenyl)prop-2-en-1-one (15)

Purified by recrystallization of ethyl acetate and hexane. Yield 23\%, mp 90.5-91 ${ }^{\circ} \mathrm{C}$; IR (FTIR/FTNIR-ATR): $1649 \mathrm{~cm}^{-1}(\mathrm{C}=\mathrm{O}) .{ }^{1} \mathrm{H}$ $\operatorname{NMR}\left(\mathrm{CDCl}_{3}, 300 \mathrm{MHz}\right) \delta: 8.22(1 \mathrm{H}, \mathrm{s}), 7.78-7.69(3 \mathrm{H}, \mathrm{m}), 7.59-7.58$ $(1 \mathrm{H}, \mathrm{m}), 7.46-7.35(5 \mathrm{H}, \mathrm{m}), 7.30-7.24(2 \mathrm{H}, \mathrm{m}), 6.71-6.68(1 \mathrm{H}, \mathrm{d}$, $J=8.7 \mathrm{~Hz}$ ), $3.86(6 \mathrm{H}, \mathrm{s}), 3.82(3 \mathrm{H}, \mathrm{s}) .{ }^{13} \mathrm{C} \mathrm{NMR}$ (DMSO- $d_{6}, 400 \mathrm{MHz}$ ) $\delta: 190.05,156.39,152.60,148.50,141.64,138.90,133.22,132.71$, $129.60,128.30,127.47,127.20,127.04,126.32,125.93,124.94,124.57$, $118.70,117.66,107.88,61.80,60.53,56.07$. HRMS $(m / z):[M+H]^{+}$ calcd. for $\mathrm{C}_{25} \mathrm{H}_{23} \mathrm{~N}_{2} \mathrm{O}_{4} \mathrm{~S} 447.1379$, found 447.1362 . 


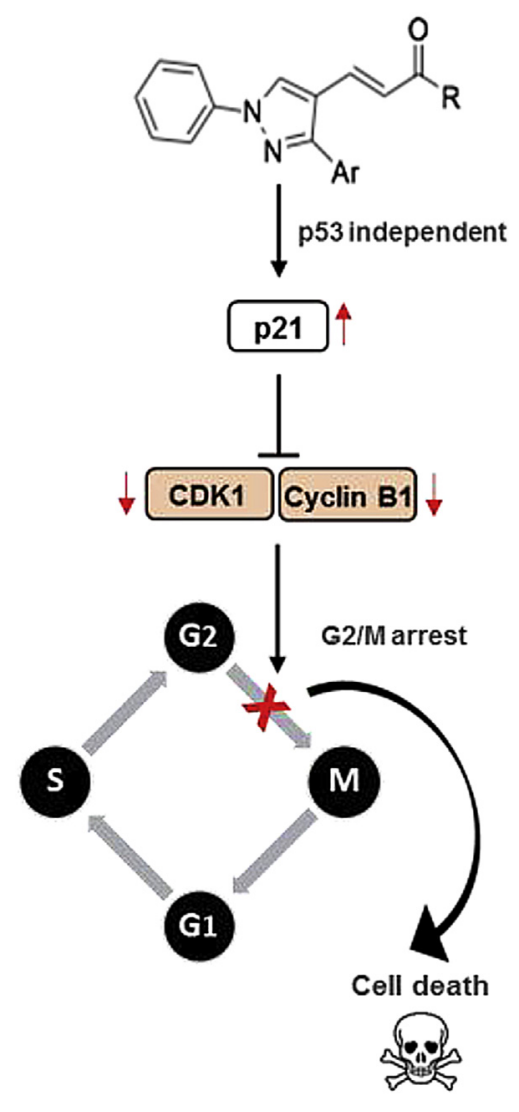

Fig. 6. Representation of molecular mechanisms initiated by pyrazolic chalcone derivatives (42 and 52). Upon treatment activation of p21 is initiated independent of p53. which then inhibits CDK1 and Cyclin B1 to form a complex resulting in cell cycle arrest at $\mathrm{G} 2 / \mathrm{M}$ phase followed by cell death.

4.1.6. (E)-1-(3,4-dimethoxyphenyl)-3-(1-phenyl-3-(thiophen-3-yl)1H-pyrazol-4-yl)prop-2-en-1-one (16)

Purified by recrystallization of ethyl acetate and hexane. Yield 62\%, mp 151-152 ${ }^{\circ} \mathrm{C}$; IR (FTIR/FTNIR-ATR): $1650 \mathrm{~cm}^{-1}(\mathrm{C}=\mathrm{O}) .{ }^{1} \mathrm{H}$ $\operatorname{NMR}\left(\mathrm{CDCl}_{3}, 300 \mathrm{MHz}\right) \delta: 8.26(1 \mathrm{H}, \mathrm{s}), 7.88(1 \mathrm{H}, \mathrm{d}, J=15.6 \mathrm{~Hz}), 7.72$ $(2 \mathrm{H}, \mathrm{d}, J=8.1 \mathrm{~Hz}), 7.60-7.53(3 \mathrm{H}, \mathrm{m}), 7.46-7.36(3 \mathrm{H}, \mathrm{m}), 7.31-7.26$ (2H, m), $7.19(1 \mathrm{H}, \mathrm{S}), 6.85(1 \mathrm{H}, \mathrm{d}, J=8.1 \mathrm{~Hz}), 3.90(6 \mathrm{H}, \mathrm{s}) .{ }^{13} \mathrm{C} \mathrm{NMR}$ $\left(\right.$ DMSO $\left.^{-} d_{6}, 400 \mathrm{MHz}\right) \delta$ : 186.89, 153.17, 148.82, 148.59, 138.94, $133.03,132.77,130.58,129.68,128.46,127.54,127.23,127.07,124.64$, $122.91,121.35,118.65,118.01,110.87,110.66,55.78,55.59$. HRMS ( $m /$ $z$ ): $[\mathrm{M}+\mathrm{H}]^{+}$calcd. for $\mathrm{C}_{24} \mathrm{H}_{21} \mathrm{~N}_{2} \mathrm{O}_{3} \mathrm{~S}$ 417.1273, found 417.1273 .

\subsection{7. (E)-1-(2,5-dimethoxyphenyl)-3-(1-phenyl-3-(thiophen-3-yl)-} 1H-pyrazol-4-yl)prop-2-en-1-one (17)

Purified by recrystallization of ethyl acetate and hexane. Yield 73\%, mp 105.5-106 ${ }^{\circ} \mathrm{C}$; IR (FTIR/FTNIR-ATR): $1649 \mathrm{~cm}^{-1}(\mathrm{C}=0) .{ }^{1} \mathrm{H}$ $\operatorname{NMR}\left(\mathrm{CDCl}_{3}, 300 \mathrm{MHz}\right) \delta: 8.18(1 \mathrm{H}, \mathrm{s}), 7.74(1 \mathrm{H}, \mathrm{s}), 7.71-7.68(2 \mathrm{H}$, $\mathrm{m}), 7.55-7.53(2 \mathrm{H}, \mathrm{m}), 7.45-7.34(1 \mathrm{H}, \mathrm{m}), 7.27(2 \mathrm{H}, \mathrm{t}, J=7.5 \mathrm{~Hz}), 7.19$ $(1 \mathrm{H}, \mathrm{d}, J=5.1 \mathrm{~Hz}), 7.15(1 \mathrm{H}, \mathrm{s}), 7.09(1 \mathrm{H}, \mathrm{d}, J=3 \mathrm{~Hz}), 6.96(1 \mathrm{H}, \mathrm{d}$, $J=3.3 \mathrm{~Hz}), 6.93(1 \mathrm{H}, \mathrm{d}, J=3 \mathrm{~Hz}), 3.77(3 \mathrm{H}, \mathrm{s}), 3.73(3 \mathrm{H}, \mathrm{s}) .{ }^{13} \mathrm{C} \mathrm{NMR}$ (DMSO-d $6,400 \mathrm{MHz}$ ) $\delta$ : 191.78, 153.00, 151.49, 148.49, 138.88, $133.63,132.69,129.61,129.44,128.50,127.44,127.19,127.05,126.29$, $124.52,118.69,118.02,117.58,113.97,113.64,56.30,55.54$. HRMS $(m /$ $z):[\mathrm{M}+\mathrm{H}]^{+}$calcd. for $\mathrm{C}_{24} \mathrm{H}_{21} \mathrm{~N}_{2} \mathrm{O}_{3} \mathrm{~S}$ 417.1273, found 417.1256 .

4.1.8. (E)-1-(2,4-dimethoxyphenyl)-3-(1-phenyl-3-(thiophen-3-yl)1H-pyrazol-4-yl)prop-2-en-1-one (18)

Purified by column flash chromatography $(0 \% \rightarrow 50 \%$ ethyl acetate in hexane). Yield $60 \%$, mp $180.5-181^{\circ} \mathrm{C}$; IR (FTIR/FTNIR-ATR):
$1642 \mathrm{~cm}^{-1}(\mathrm{C}=\mathrm{O}) .{ }^{1} \mathrm{H}$ NMR $\left(\mathrm{CDCl}_{3}, 300 \mathrm{MHz}\right) \delta: 8.17(1 \mathrm{H}, \mathrm{s})$, $7.78-7.66(4 \mathrm{H}, \mathrm{m}), 7.58-7.56(1 \mathrm{H}, \mathrm{m}), 7.46-7.24(6 \mathrm{H}, \mathrm{m}), 6.50$ $(1 \mathrm{H}, \mathrm{d}, J=10.5 \mathrm{~Hz}), 6.42(1 \mathrm{H}, \mathrm{s}), 3.80(6 \mathrm{H}, \mathrm{s}) .{ }^{13} \mathrm{C}$ NMR (DMSO-d $400 \mathrm{MHz}$ ) $\delta$ : 189.28, 163.74, 159.95, 148.40, 138.93, 132.81, 131.87, $131.75,129.60,128.28,127.52,127.14,126.98,126.55,124.56,121.45$, 118.70, 117.85, 105.85, 98.53, 55.92, 55.57. HRMS $(m / z):[\mathrm{M}+\mathrm{H}]^{+}$ calcd. for $\mathrm{C}_{24} \mathrm{H}_{21} \mathrm{~N}_{2} \mathrm{O}_{3} \mathrm{~S}$ 417.1273, found 417.1267.

4.1.9. (E)-1-(benzo[d][1,3]dioxol-5-yl)-3-(1-phenyl-3-(thiophen-3yl)-1H-pyrazol-4-yl)prop-2-en-1-one (19)

Purified by column flash chromatography $(0 \% \rightarrow 50 \%$ ethyl acetate in hexane). Yield $81 \%$ as a colorless oil; IR (FTIR/FTNIR-ATR): $1646 \mathrm{~cm}^{-1}(\mathrm{C}=\mathrm{O}) .{ }^{1} \mathrm{H}$ NMR $\left(\mathrm{CDCl}_{3}, 400 \mathrm{MHz}\right) \delta: 8.31(1 \mathrm{H}, \mathrm{s}), 7.93$ $(1 \mathrm{H}, \mathrm{d}, J=15.6 \mathrm{~Hz}), 7.78(2 \mathrm{H}, \mathrm{d}, J=8 \mathrm{~Hz}), 7.65-7.64(1 \mathrm{H}, \mathrm{m}), 7.59$ $(1 \mathrm{H}, \mathrm{dd}, J=2 \mathrm{~Hz}, J=8 \mathrm{~Hz}), 7.52-7.44(5 \mathrm{H}, \mathrm{m}), 7.36-7.32(2 \mathrm{H}, \mathrm{m})$, $6.88(1 \mathrm{H}, \mathrm{d}, J=8.4 \mathrm{~Hz}), 6.06(2 \mathrm{H}, \mathrm{s}) .{ }^{13} \mathrm{C}$ NMR (DMSO- $\left.d_{6}, 400 \mathrm{MHz}\right)$ $\delta: 186.43,151.47,148.62,148.01,138.92,133.35,132.70,132.32$, 129.67, 128.42, 127.49, 127.22, 127.08, 124.61, 124.57, 121.27, 118.59, 117.99, 108.15, 107.65, 102.09. HRMS $(\mathrm{m} / \mathrm{z}):[\mathrm{M}+\mathrm{H}]^{+}$calcd. for $\mathrm{C}_{23} \mathrm{H}_{17} \mathrm{~N}_{2} \mathrm{O}_{3} \mathrm{~S}$ 401.0960, found 401.0954 .

4.1.10. (E)-3-(3-(benzo[d][1,3]dioxol-5-yl)-1-phenyl-1H-pyrazol-4yl)-1-phenylprop-2-en-1-one (20)

Purified by column flash chromatography $(0 \% \rightarrow 30 \%$ ethyl acetate in hexane). Yield $95 \%, \mathrm{mp} 163.5-164{ }^{\circ} \mathrm{C}$; IR (FTIR/FTNIR-ATR): $1662 \mathrm{~cm}^{-1}(\mathrm{C}=\mathrm{O}) .{ }^{1} \mathrm{H}$ NMR $\left(\mathrm{CDCl}_{3}, 300 \mathrm{MHz}\right) \delta: 8.27(1 \mathrm{H}, \mathrm{s}), 7.90$ $(2 \mathrm{H}, \mathrm{d}, J=8.7 \mathrm{~Hz}), 7.79(1 \mathrm{H}, \mathrm{d}, J=15.6 \mathrm{~Hz}), 7.72(2 \mathrm{H}, \mathrm{d}, J=9.6 \mathrm{~Hz})$, 7.51-7.40 (5H, m), 7.34-7.28 (2H, m), 7.14-7.07 (2H, m), $6.86(1 \mathrm{H}, \mathrm{d}$, $J=8.1 \mathrm{~Hz}$ ), $5.96(2 \mathrm{H}, \mathrm{s}) .{ }^{13} \mathrm{C}$ NMR (DMSO-d, $\left.400 \mathrm{MHz}\right) \delta: 189.22$, 153.16, 148.28, 148.21, 139.40, 138.15, 134.80, 133.50, 130.14, 129.24, 129.18, 128.66, 127.57, 126.17, 122.91, 121.74, 119.10, 118.10, 109.14, 108.97, 101.86. HRMS $(\mathrm{m} / \mathrm{z})$ : $[\mathrm{M}+\mathrm{H}]^{+}$calcd. for $\mathrm{C}_{25} \mathrm{H}_{19} \mathrm{~N}_{2} \mathrm{O}_{3}$ 395.1396, found 395.1399.

4.1.11. (E)-3-(3-(benzo[d][1,3]dioxol-5-yl)-1-phenyl-1H-pyrazol-4yl)-1-(3,4,5-trimethoxyphenyl)prop-2-en-1-one (21)

Purified by column flash chromatography $(0 \% \rightarrow 30 \%$ ethyl acetate in hexane). Yield 53\%, mp $163.5-164{ }^{\circ} \mathrm{C}$; IR (FTIR/FTNIRATR): $1656 \mathrm{~cm}^{-1}(\mathrm{C}=\mathrm{O}) .{ }^{1} \mathrm{H}$ NMR $\left(\mathrm{CDCl}_{3}, 300 \mathrm{MHz}\right) \delta: 8.32(1 \mathrm{H}, \mathrm{s})$, 7.89-7.77 (3H, m), 7.52-7.14 (8H, m), $6.93(1 \mathrm{H}, \mathrm{d}, J=8.1 \mathrm{~Hz}), 6.02$ $(2 \mathrm{H}, \mathrm{s}), 3.93(9 \mathrm{H}, \mathrm{s}) .{ }^{13} \mathrm{C}$ NMR (DMSO- $\left.d_{6}, 400 \mathrm{MHz}\right) \delta: 187.52,152.90$, 152.65, 147.80, 147.72, 141.96, 138.92, 134.11, 133.06, 129.68, 128.80, $127.13,125.79,122.47,121.12,118.77,117.60,108.66,108.54,106.00$, 101.40, 60.20, 56.21. HRMS (m/z): $[\mathrm{M}+\mathrm{H}]^{+}$calcd. for $\mathrm{C}_{28} \mathrm{H}_{25} \mathrm{~N}_{2} \mathrm{O}_{6}$ 485.1713, found 485.1716 .

4.1.12. (E)-3-(3-(benzo[d][1,3]dioxol-5-yl)-1-phenyl-1H-pyrazol-4yl)-1-(2,4,6-trimethoxyphenyl)prop-2-en-1-one (22)

Purified by column flash chromatography $(0 \% \rightarrow 50 \%$ ethyl acetate in hexane). Yield $40 \%, \mathrm{mp} 205-205.5^{\circ} \mathrm{C}$; IR (FTIR/FTNIR-ATR): $1650 \mathrm{~cm}^{-1}(\mathrm{C}=\mathrm{O}) .{ }^{1} \mathrm{H}$ NMR $\left(\mathrm{CDCl}_{3}, 300 \mathrm{MHz}\right) \delta: 8.15(1 \mathrm{H}, \mathrm{s}), 7.67$ $(2 \mathrm{H}, \mathrm{d}, J=7.8 \mathrm{~Hz}), 7.44-7.35(3 \mathrm{H}, \mathrm{m}), 7.29-7.24(1 \mathrm{H}, \mathrm{m}), 7.05-7.02$ $(2 \mathrm{H}, \mathrm{m}), 6.81-6.67(2 \mathrm{H}, \mathrm{m}), 6.07(2 \mathrm{H}, \mathrm{s}), 5.94(2 \mathrm{H}, \mathrm{s}), 3.77(3 \mathrm{H}, \mathrm{s})$, $3.73(6 \mathrm{H}, \mathrm{s}) .{ }^{13} \mathrm{C}$ NMR (DMSO-d, $\left.400 \mathrm{MHz}\right) \delta: 193.40,161.81,157.81$, $151.95,147.72$, 147.71, 138.92, 135.15, 129.61, 128.60, 128.46, 127.01, 125.59, 122.02, 118.64, 116.84, 110.53, 108.56, 108.16, 101.40, 90.84, 55.73, 55.44. HRMS (m/z): $[\mathrm{M}+\mathrm{H}]^{+}$calcd. for $\mathrm{C}_{28} \mathrm{H}_{25} \mathrm{~N}_{2} \mathrm{O}_{6} 485.1713$, found 485.1712 .

4.1.13. (E)-3-(3-(benzo[d][1,3]dioxol-5-yl)-1-phenyl-1H-pyrazol-4yl)-1-(2,3,4-trimethoxyphenyl)prop-2-en-1-one (23)

Purified by recrystallization of ethyl acetate and hexane. Yield 27\%, mp 144.5-145 ${ }^{\circ} \mathrm{C}$; IR (FTIR/FTNIR-ATR): $1657 \mathrm{~cm}^{-1}(\mathrm{C}=0) .{ }^{1} \mathrm{H}$ $\operatorname{NMR}\left(\mathrm{CDCl}_{3}, 300 \mathrm{MHz}\right) \delta: 8.22(1 \mathrm{H}, \mathrm{s}), 7.72-7.65(3 \mathrm{H}, \mathrm{m}), 7.45-7.38$ $(3 \mathrm{H}, \mathrm{m}), 7.29-7.22(2 \mathrm{H}, \mathrm{m}), 7.13-7.07(2 \mathrm{H}, \mathrm{m}), 6.85(1 \mathrm{H}, \mathrm{d}$, 
$J=7.8 \mathrm{~Hz}), 6.69(1 \mathrm{H}, \mathrm{d}, J=8.7 \mathrm{~Hz}), 5.95(2 \mathrm{H}, \mathrm{s}), 3.85(6 \mathrm{H}, \mathrm{s}), 3.82$ $(3 \mathrm{H}, \mathrm{s}) .{ }^{13} \mathrm{C}$ NMR (DMSO- $\left.d_{6}, 400 \mathrm{MHz}\right) \delta: 190.03,156.38,152.63$, $152.45,147.75,147.69,141.64,138.93,133.46,129.60,128.49,127.01$, $126.30,125.77,124.94,122.40,118.71,117.37,108.61,108.50,107.83$, 101.37, 61.80, 60.53, 56.06. HRMS $(\mathrm{m} / \mathrm{z})$ : $[\mathrm{M}+\mathrm{H}]^{+}$calcd. for $\mathrm{C}_{28} \mathrm{H}_{25} \mathrm{~N}_{2} \mathrm{O}_{6}$ 485.1713, found 485.1711.

\subsubsection{4. (E)-3-(3-(benzo[d][1,3]dioxol-5-yl)-1-phenyl-1H-pyrazol-4-} yl)-1-(3,4-dimethoxyphenyl)prop-2-en-1-one (24)

Purified by column flash chromatography $(0 \% \rightarrow 30 \%$ ethyl acetate in hexane). Yield $45 \%, \mathrm{mp} 158.5-159^{\circ} \mathrm{C}$; IR (FTIR/FTNIR-ATR): $1649 \mathrm{~cm}^{-1}(\mathrm{C}=\mathrm{O}) .{ }^{1} \mathrm{H}$ NMR $\left(\mathrm{CDCl}_{3}, 300 \mathrm{MHz}\right) \delta: 8.26(1 \mathrm{H}, \mathrm{s}), 7.79$ $(1 \mathrm{H}, \mathrm{d}, J=15.3 \mathrm{~Hz}), 7.71(2 \mathrm{H}, \mathrm{d}, J=7.8 \mathrm{~Hz}), 7.45-7.40(2 \mathrm{H}, \mathrm{m})$, $7.56-7.52(2 \mathrm{H}, \mathrm{m}), 7.33(1 \mathrm{H}, \mathrm{d}, J=15.6 \mathrm{~Hz}), 7.27(1 \mathrm{H}, \mathrm{d}, J=7.5 \mathrm{~Hz})$, $7.14(1 \mathrm{H}, \mathrm{s}), 7.10(1 \mathrm{H}, \mathrm{d}, J=9.6 \mathrm{~Hz}), 6.88(1 \mathrm{H}, \mathrm{s}), 6.84(1 \mathrm{H}, \mathrm{d}$, $J=8.4 \mathrm{~Hz}), 5.96(2 \mathrm{H}, \mathrm{s}), 3.89(6 \mathrm{H}, \mathrm{s}) .{ }^{13} \mathrm{C}$ NMR (DMSO- $\left.d_{6}, 400 \mathrm{MHz}\right)$ $\delta: 186.93,153.15,152.53,148.81,147.76,147.72,138.96,133.25$, $130.56,129.66,128.56,127.04,125.81,122.89,122.41,121.19,118.64$, $117.71,110.86,110.66,108.65,108.50,101.38,55.77,55.57$. HRMS ( $m /$ $z):[\mathrm{M}+\mathrm{H}]^{+}$calcd. for $\mathrm{C}_{27} \mathrm{H}_{23} \mathrm{~N}_{2} \mathrm{O}_{5}$ 455.1607, found 455.1606 .

4.1.15. (E)-3-(3-(benzo[d][1,3]dioxol-5-yl)-1-phenyl-1H-pyrazol-4yl)-1-(2,5-dimethoxyphenyl)prop-2-en-1-one (25)

Purified by column flash chromatography $(0 \% \rightarrow 50 \%$ ethyl acetate in hexane). Yield $28 \%, \mathrm{mp} 125-126^{\circ} \mathrm{C}$; IR (FTIR/FTNIR-ATR): $1652 \mathrm{~cm}^{-1}(\mathrm{C}=\mathrm{O}) .{ }^{1} \mathrm{H}$ NMR $\left(\mathrm{CDCl}_{3}, 300 \mathrm{MHz}\right) \delta: 8.18(1 \mathrm{H}, \mathrm{s})$, $7.71-7.68(2 \mathrm{H}, \mathrm{d}, J=9.9 \mathrm{~Hz}), 7.60(1 \mathrm{H}, \mathrm{d}, J=16.2 \mathrm{~Hz}), 7.44-7.39(2 \mathrm{H}$, m), 7.29-7.24 (1H, m), $7.16(1 \mathrm{H}, \mathrm{s}), 7.11(1 \mathrm{H}, \mathrm{m}), 7.08-7.05(2 \mathrm{H}, \mathrm{m})$, $6.94(1 \mathrm{H}, \mathrm{d}, J=3.3 \mathrm{~Hz}), 6.86-6.82(2 \mathrm{H}, \mathrm{m}), 5.96(2 \mathrm{H}, \mathrm{s}), 3.77(3 \mathrm{H}, \mathrm{s})$, $3.73(3 \mathrm{H}, \mathrm{s}) .{ }^{13} \mathrm{C}$ NMR (DMSO- $\left.d_{6}, 400 \mathrm{MHz}\right) \delta: 192.04,153.00,152.42$, 151.37, 147.76, 147.69, 138.91, 134.15, 129.60, 129.41, 128.64, 127.04, 126.16, 125.71, 122.33, 118.71, 117.92, 117.24, 113.92, 113.55, 108.56, $108.44,101.39,56.26,55.54$. HRMS $(m / z):[\mathrm{M}+\mathrm{H}]^{+}$calcd. for $\mathrm{C}_{27} \mathrm{H}_{23} \mathrm{~N}_{2} \mathrm{O}_{5}$ 455.1607, found 455.1608 .

4.1.16. (E)-3-(3-(benzo[d][1,3]dioxol-5-yl)-1-phenyl-1H-pyrazol-4yl)-1-(2,4-dimethoxyphenyl)prop-2-en-1-one (26)

Purified by recrystallization of ethyl acetate and hexane. Yield 28\%, mp 154,8-155.3 ${ }^{\circ} \mathrm{C}$; IR (FTIR/FTNIR-ATR): $1645 \mathrm{~cm}^{-1}$ (C=O). ${ }^{1} \mathrm{H}$ NMR $\left(\mathrm{CDCl}_{3}, 300 \mathrm{MHz}\right) \delta: 8.17(1 \mathrm{H}, \mathrm{s}), 7.71-7.62(4 \mathrm{H}, \mathrm{m})$, 7.44-7.39 (2H, m), 7.29-7.22 (2H, m), 7.13-7.07 (2H, m), $6.84(1 \mathrm{H}$, $\mathrm{d}, J=8.1 \mathrm{~Hz}), 6.49(1 \mathrm{H}, \mathrm{d}, J=10.8 \mathrm{~Hz}), 6.14(1 \mathrm{H}, \mathrm{s}), 5.95(2 \mathrm{H}, \mathrm{s}), 3.08$ $(6 \mathrm{H}, \mathrm{s}) .{ }^{13} \mathrm{C}$ NMR (DMSO-d, $\left.400 \mathrm{MHz}\right) \delta: 189.51,163.68,159.87$, $152.33,147.70,147.65,138.96,132.19,131.84,129.57,128.39,126.94$, $126.41,125.89,122.37,121.43,118.70,117.53,108.60,108.50,105.81$, 101.36, 98.51, 55.87, 55.54. HRMS $(\mathrm{m} / \mathrm{z}):[\mathrm{M}+\mathrm{H}]^{+}$calcd. for $\mathrm{C}_{27} \mathrm{H}_{23} \mathrm{~N}_{2} \mathrm{O}_{5}$ 455.1607, found 455.1607 .

4.1.17. (E)-3-(3-(benzo[d][1,3]dioxol-5-yl)-1-phenyl-1H-pyrazol-4yl)-1-(thiophen-3-yl)prop-2-en-1-one (27)

Purified by recrystallization of ethyl acetate and hexane. Yield 56\%, mp 138.5-139.5 ${ }^{\circ} \mathrm{C}$; IR (FTIR/FTNIR-ATR): $1659 \mathrm{~cm}^{-1}(\mathrm{C}=0)$. ${ }^{1} \mathrm{H}$ NMR $\left(\mathrm{CDCl}_{3}, 300 \mathrm{MHz}\right) \delta: 8.25(1 \mathrm{H}, \mathrm{s}), 8.01-8.02(1 \mathrm{H}, \mathrm{m}), 7.78$ $(1 \mathrm{H}, \mathrm{d}, J=15.6 \mathrm{~Hz}), 7.70(2 \mathrm{H}, \mathrm{d}, J=8.4 \mathrm{~Hz}), 7.56(1 \mathrm{H}, \mathrm{d}, J=6 \mathrm{~Hz})$, 7.45-7.39 (2H, m), 7.30-7.06 (5H, m), $6.86(1 \mathrm{H}, \mathrm{d}, J=7.8 \mathrm{~Hz}), 5.96$ $(2 \mathrm{H}, \mathrm{s}) .{ }^{13} \mathrm{C}$ NMR (DMSO-d, $\left.400 \mathrm{MHz}\right) \delta: 182.77,152.57,147.78$, 147.72, 142.90, 138.93, 133.31, 133.18, 129.68, 128.46, 127.75, 127.10, 126.93, 125.72, 122.65, 122.39, 118.65, 117.58, 108.66, 108.46, 101.38. HRMS $(m / z):[\mathrm{M}+\mathrm{H}]^{+}$calcd. for $\mathrm{C}_{23} \mathrm{H}_{17} \mathrm{~N}_{2} \mathrm{O}_{3} \mathrm{~S}$ 401.0960, found 401.0964 .

4.1.18. (E)-3-(3-(benzo[d][1,3]dioxol-5-yl)-1-phenyl-1H-pyrazol-4yl)-1-(pyridin-2-yl)prop-2-en-1-one (28)

Purified by recrystallization of ethyl acetate and hexane. Yield 83\%, mp 188.5-189.2 ${ }^{\circ} \mathrm{C}$; IR (FTIR/FTNIR-ATR): $1650 \mathrm{~cm}^{-1}(\mathrm{C}=0)$.
${ }^{1} \mathrm{H}$ NMR $\left(\mathrm{CDCl}_{3}, 300 \mathrm{MHz}\right) \delta: 8.88(1 \mathrm{H}, \mathrm{d}, J=4.4 \mathrm{~Hz}), 8.42(1 \mathrm{H}, \mathrm{s})$, 8.14-7.72 $(6 \mathrm{H}, \mathrm{m}), 7.46-7.28(4 \mathrm{H}, \mathrm{m}), 7.16(1 \mathrm{H}, \mathrm{s}), 7.12(1 \mathrm{H}, \mathrm{d}$, $J=9.9 \mathrm{~Hz}), 6.88(1 \mathrm{H}, \mathrm{d}, J=7.8 \mathrm{~Hz}), 5.97(2 \mathrm{H}, \mathrm{s}) .{ }^{13} \mathrm{C}$ NMR (DMSO-d $d_{6}$, $400 \mathrm{MHz}) \delta: 188.58,153.57,152.91,149.01,147.84,147.75,138.95$, $137.71,134.72,129.59,128.71,127.50,127.04,125.69,122.56,122.48$ 120.20, 118.75, 117.63, 108.68, 108.61, 101.41. HRMS $(\mathrm{m} / \mathrm{z}):[\mathrm{M}+\mathrm{H}]^{+}$ calcd. for $\mathrm{C}_{24} \mathrm{H}_{18} \mathrm{~N}_{3} \mathrm{O}_{3} 396.1348$, found 396.1344.

4.1.19. (E)-3-(3-(benzo[d][1,3]dioxol-5-yl)-1-phenyl-1H-pyrazol-4yl)-1-(pyridin-3-yl)prop-2-en-1-one (29)

Purified by column flash chromatography $(0 \% \rightarrow 50 \%$ ethyl acetate in hexane). Yield $10 \%, \mathrm{mp} 174-176.5^{\circ} \mathrm{C}$; IR (FTIR/FTNIR-ATR): $1660 \mathrm{~cm}^{-1}(\mathrm{C}=\mathrm{O}) .{ }^{1} \mathrm{H}$ NMR $\left(\mathrm{CDCl}_{3}, 400 \mathrm{MHz}\right) \delta: 9.17(1 \mathrm{H}, \mathrm{s}), 8.78$ $(1 \mathrm{H}, \mathrm{dd}, J=1.6 \mathrm{~Hz}, J=4.8 \mathrm{~Hz}), 8.36(1 \mathrm{H}, \mathrm{s}), 8.25(1 \mathrm{H}, \mathrm{dt}, J=2 \mathrm{~Hz}$, $J=8 \mathrm{~Hz}), 7.93-7.89(1 \mathrm{H}, \mathrm{d}, J=15.6 \mathrm{~Hz}), 7.79(2 \mathrm{H}, \mathrm{d}, J=7.6 \mathrm{~Hz})$ $7.52-7.48(2 \mathrm{H}, \mathrm{m}), 7.46-7.42(1 \mathrm{H}, \mathrm{m}), 7.38-7.32(2 \mathrm{H}, \mathrm{m}), 7.19(1 \mathrm{H}$, s), $7.14(1 \mathrm{H}, \mathrm{dd}, J=1.6 \mathrm{~Hz}, J=7.6 \mathrm{~Hz}), 6.94(1 \mathrm{H}, \mathrm{d}, J=8 \mathrm{~Hz}), 5.97(2 \mathrm{H}$, s). ${ }^{13} \mathrm{C}$ NMR (DMSO- $\left.d_{6}, 400 \mathrm{MHz}\right) \delta: 187.82,153.28,152.86,149.40$, 147.86, 147.77, 138.88, 135.62, 135.01, 132.90, 129.72, 128.92, 127.20, 125.58, 123.99, 122.46, 120.95, 118.65, 117.53, 108.69, 108.49, 101.41. HRMS $(m / z):[\mathrm{M}+\mathrm{H}]^{+}$calcd. for $\mathrm{C}_{24} \mathrm{H}_{18} \mathrm{~N}_{3} \mathrm{O}_{3}$ 396.1348, found 396.1330 .

4.1.20. (E)-1-(benzo[d][1,3]dioxol-5-yl)-3-(3-(benzo[d] [1,3]dioxol5-yl)-1-phenyl-1H-pyrazol-4-yl)prop-2-en-1-one (30)

Purified by recrystallization of ethyl acetate and hexane. Yield 51\%, mp 169.5-170 ${ }^{\circ} \mathrm{C}$; IR (FTIR/FTNIR-ATR): $1644 \mathrm{~cm}^{-1}(\mathrm{C}=\mathrm{O}) .{ }^{1} \mathrm{H}$ $\operatorname{NMR}\left(\mathrm{CDCl}_{3}, 300 \mathrm{MHz}\right) \delta: 8.25(1 \mathrm{H}, \mathrm{s}), 7.78(1 \mathrm{H}, \mathrm{d}, J=16.5 \mathrm{~Hz}), 7.71$ $(2 \mathrm{H}, \mathrm{d}, J=7.8 \mathrm{~Hz}), 7.53(1 \mathrm{H}, \mathrm{d}, J=9.9 \mathrm{~Hz}), 7.45-7.40(3 \mathrm{H}, \mathrm{m})$, $7.30-7.07(4 \mathrm{H}, \mathrm{m}), 6.84(1 \mathrm{H}, \mathrm{qd}, J=1.6 \mathrm{~Hz}, J=9.3 \mathrm{~Hz}), 6.00(2 \mathrm{H}, \mathrm{s})$, $5.96(2 \mathrm{H}, \mathrm{s}) .{ }^{13} \mathrm{C}$ NMR (DMSO- $\left.d_{6}, 400 \mathrm{MHz}\right) \delta: 186.44,152.56,151.44$, 147.99, 147.76, 147.71, 138.94, 133.55, 132.32, 129.65, 128.53, 127.04, 125.75, 124.54, 122.38, 121.09, 118.58, 117.71, 108.63, 108.46, 108.27, 107.65, 102.08, 101.37. HRMS $(m / z)$ : $[\mathrm{M}+\mathrm{H}]^{+}$calcd. for $\mathrm{C}_{26} \mathrm{H}_{19} \mathrm{~N}_{2} \mathrm{O}_{5}$ 439.1294, found 439.1304.

4.1.21. (E)-3-(3-(benzo[d][1,3]dioxol-5-yl)-1-phenyl-1H-pyrazol-4yl)-1-(1H-pyrrol-3-yl)prop-2-en-1-one (31)

Purified by column flash chromatography $(0 \% \rightarrow 50 \%$ ethyl acetate in hexane). Yield $11 \%, \mathrm{mp} 200-203^{\circ} \mathrm{C}$; IR (FTIR/FTNIR-ATR): $1638 \mathrm{~cm}^{-1}(\mathrm{C}=\mathrm{O}) .{ }^{1} \mathrm{H}$ NMR $\left(\mathrm{CDCl}_{3}, 400 \mathrm{MHz}\right) \delta: 9.50(1 \mathrm{H}, \mathrm{s}), 8.30$ $(1 \mathrm{H}, \mathrm{s}), 7.84(1 \mathrm{H}, \mathrm{d}, J=15.6 \mathrm{~Hz}), 7.78(2 \mathrm{H}, \mathrm{d}, J=7.6 \mathrm{~Hz}), 7.50-7.47$ $(2 \mathrm{H}, \mathrm{m}), 7.36-7.32(1 \mathrm{H}, \mathrm{m}), 7.21-7.16(3 \mathrm{H}, \mathrm{m}), 7.08(1 \mathrm{H}, \mathrm{s})$, 6.95-6.92 (3H, m), 6.34-6.32 (1H, m), $6.03(2 \mathrm{H}, \mathrm{s}) .{ }^{13} \mathrm{C}$ NMR (DMSO-d $\left.d_{6}, 400 \mathrm{MHz}\right) \delta: 177.61,152.27,147.69,139.01,132.99,130.71$, 130.53, 129.66, 128.16, 126.97, 126.24, 125.92, 122.72, 122.38, 118.58, $117.75,116.63,110.09,108.66,108.50,101.36$. HRMS $(m / z):[\mathrm{M}+\mathrm{H}]^{+}$ calcd. for $\mathrm{C}_{23} \mathrm{H}_{18} \mathrm{~N}_{3} \mathrm{O}_{3} 384.1348$, found 384.1347 .

\subsubsection{2. (E)-3-(1-phenyl-3-(pyridin-3-yl)-1H-pyrazol-4-yl)-1-}

(thiophen-3-yl)prop-2-en-1-one (32)

Purified by column flash chromatography $(0 \% \rightarrow 50 \%$ ethyl acetate in hexane). Yield $82 \%, \mathrm{mp} 172-173^{\circ} \mathrm{C}$; IR (FTIR/FTNIR-ATR): $1655 \mathrm{~cm}^{-1}(\mathrm{C}=\mathrm{O}) .{ }^{1} \mathrm{H}$ NMR $\left(\mathrm{CDCl}_{3}, 400 \mathrm{MHz}\right) \delta: 8.99(1 \mathrm{H}, \mathrm{d}$, $J=1.6 \mathrm{~Hz}), 8.69(1 \mathrm{H}, \mathrm{dd}, J=1.6 \mathrm{~Hz}, J=5.2 \mathrm{~Hz}), 8.37(1 \mathrm{H}, \mathrm{s}), 8.07(1 \mathrm{H}$, $\mathrm{dd}, J=1.2 \mathrm{~Hz}, J=2.8 \mathrm{~Hz}), 8.01(1 \mathrm{H}, \mathrm{dt}, J=2 \mathrm{~Hz}, J=8 \mathrm{~Hz}), 7.84-7.79$ $(3 \mathrm{H}, \mathrm{m}), 7.61(1 \mathrm{H}, \mathrm{dd}, J=1.2 \mathrm{~Hz}, J=4.8 \mathrm{~Hz}), 7.54-7.50(2 \mathrm{H}, \mathrm{m})$, $7.45-7.35(3 \mathrm{H}, \mathrm{m}), 7.23(1 \mathrm{H}, \mathrm{d}, J=16.4 \mathrm{~Hz}) .{ }^{13} \mathrm{C}$ NMR (DMSO-d 6 , $400 \mathrm{MHz}) \delta: 182.69,149.93,149.68,148.73,142.81,138.84,135.77$, 133.47, 132.40, 129.74, 128.88, 127.91, 127.82, 127.39, 126.92, 123.94, 123.30, 118.81, 118.14. HRMS (m/z): $[\mathrm{M}+\mathrm{H}]^{+}$calcd. for $\mathrm{C}_{21} \mathrm{H}_{16} \mathrm{~N}_{3} \mathrm{OS}$ 358.1014, found 358.1004. 
4.1.23. (E)-3-(1-phenyl-3-(pyridin-3-yl)-1H-pyrazol-4-yl)-1-

(pyridin-2-yl)prop-2-en-1-one (33)

Purified by column flash chromatography $(0 \% \rightarrow 40 \%$ ethyl acetate in hexane) then by recrystallization of ethyl acetate and hexane. Yield 11\%, $\mathrm{mp} 187.5-188{ }^{\circ} \mathrm{C}$; IR (FTIR/FTNIR-ATR): $1664 \mathrm{~cm}^{-1}(\mathrm{C}=\mathrm{O}) .{ }^{1} \mathrm{H}$ NMR $\left(\mathrm{CDCl}_{3}, 400 \mathrm{MHz}\right) \delta: 9.00(1 \mathrm{H}, \mathrm{d}$, $J=1.2 \mathrm{~Hz}), 8.72(1 \mathrm{H}, \mathrm{d}, J=4 \mathrm{~Hz}), 8.69(1 \mathrm{H}, \mathrm{dd}, J=1.6 \mathrm{~Hz}, J=5.2 \mathrm{~Hz})$, $8.52(1 \mathrm{H}, \mathrm{s}), 8.18(1 \mathrm{H}, \mathrm{d}, J=8 \mathrm{~Hz}), 8.14(1 \mathrm{H}, \mathrm{d}, J=16 \mathrm{~Hz}), 8.03(1 \mathrm{H}, \mathrm{d}$, $J=7.6 \mathrm{~Hz}), 7.98-7.94(1 \mathrm{H}, \mathrm{m}), 7.90-7.86(1 \mathrm{H}, \mathrm{m}), 7.83-7.77(1 \mathrm{H}, \mathrm{m})$, $7.54-7.34(6 \mathrm{H}, \mathrm{m}) .{ }^{13} \mathrm{C}$ NMR (DMSO- $\left.d_{6}, 400 \mathrm{MHz}\right) \delta: 188.50,153.43$, 150.24, 149.71, 149.01, 148.84, 138.83, 137.73, 135.92, 133.89, 129.63, $129.15,127.90,127.55,127.31,123.93,122.49,120.80,118.87,118.14$. HRMS $(m / z):[\mathrm{M}+\mathrm{H}]^{+}$calcd. for $\mathrm{C}_{22} \mathrm{H}_{17} \mathrm{~N}_{4} \mathrm{O}$ 353.1402, found 353.1398 .

4.1.24. (E)-1-(benzo[d][1,3]dioxol-5-yl)-3-(1-phenyl-3-(pyridin-3yl)-1H-pyrazol-4-yl)prop-2-en-1-one (34)

Purified by column flash chromatography $(0 \% \rightarrow 50 \%$ ethyl acetate in hexane). Yield $82 \%, \mathrm{mp} 204-204.6^{\circ} \mathrm{C}$; IR (FTIR/FTNIR-ATR): $1663 \mathrm{~cm}^{-1}(\mathrm{C}=\mathrm{O}) .{ }^{1} \mathrm{H}$ NMR $\left(\mathrm{CDCl}_{3}, 400 \mathrm{MHz}\right) \delta: 8.99(1 \mathrm{H}, \mathrm{d}$, $J=1.6 \mathrm{~Hz}), 8.69(1 \mathrm{H}, \mathrm{dd}, J=1.6 \mathrm{~Hz}, J=5 \mathrm{~Hz}), 8.37(1 \mathrm{H}, \mathrm{s}), 8.01(1 \mathrm{H}$, $\mathrm{dt}, J=2 \mathrm{~Hz}, J=5 \mathrm{~Hz}), 7.83-7.79(3 \mathrm{H}, \mathrm{m}), 7.56(1 \mathrm{H}, \mathrm{dd}, J=2 \mathrm{~Hz}$, $J=8.4 \mathrm{~Hz}), 7.54-7.48(3 \mathrm{H}, \mathrm{m}), 7.44-7.35(2 \mathrm{H}, \mathrm{m}), 7.31(1 \mathrm{H}, \mathrm{s}), 6.87$ $(1 \mathrm{H}, \mathrm{d}, J=8.4 \mathrm{~Hz}), 6.06(2 \mathrm{H}, \mathrm{s}) .{ }^{13} \mathrm{C}$ NMR (DMSO- $\left.d_{6}, 400 \mathrm{MHz}\right) \delta$ : $186.40,151.53,149.93,149.65,148.74,148.02,138.85,135.78,132.76$, 132.22, 129.73, 128.93, 127.94, 127.36, 124.64, 123.93, 121.78, 118.76, 118.27, 108.16, 107.67, 102.12. HRMS $(\mathrm{m} / \mathrm{z})$ : $[\mathrm{M}+\mathrm{H}]^{+}$calcd. for $\mathrm{C}_{24} \mathrm{H}_{18} \mathrm{~N}_{3} \mathrm{O}_{3} 396.1348$, found 396.1344 .

\subsubsection{5. (E)-3-(1-phenyl-3-(pyridin-3-yl)-1H-pyrazol-4-yl)-1-(1H-} pyrrol-3-yl)prop-2-en-1-one (35)

Purified by column flash chromatography $(0 \% \rightarrow 2 \%$ methanol in ethyl acetate). Yield $15 \%$, mp $211.8-212.5^{\circ} \mathrm{C}$; IR (FTIR/FTNIR-ATR): $1644 \mathrm{~cm}^{-1}(\mathrm{C}=\mathrm{O}),{ }^{1} \mathrm{H}$ NMR $\left(\mathrm{CDCl}_{3}, 400 \mathrm{MHz}\right) \delta: 9.55(1 \mathrm{H}, \mathrm{s}), 9.00$ $(1 \mathrm{H}, \mathrm{s}), 8.69(1 \mathrm{H}, \mathrm{d}, J=4.8 \mathrm{~Hz}), 8.36(1 \mathrm{H}, \mathrm{s}), 8.01(1 \mathrm{H}, \mathrm{dd}, J=2 \mathrm{~Hz}$, $J=8 \mathrm{~Hz}), 7.83-7.79(3 \mathrm{H}, \mathrm{m}), 7.53-7.49(2 \mathrm{H}, \mathrm{m}), 7.44-7.35(2 \mathrm{H}, \mathrm{m})$, $7.18(1 \mathrm{H}, \mathrm{d}, J=15.6 \mathrm{~Hz}), 7.09-7.08(1 \mathrm{H}, \mathrm{m}), 6.95-6.93(1 \mathrm{H}, \mathrm{m})$, $6.34-6.32(1 \mathrm{H}, \mathrm{m}) .{ }^{13} \mathrm{C}$ NMR (DMSO- $\left.d_{6}, 400 \mathrm{MHz}\right) \delta: 177.48,149.61$, 148.76, 138.92, 135.81, 132.95, 129.79, 129.73, 128.60, 128.13, 127.28, $126.40,123.96,123.37,118.75,118.31,116.78,110.07$. HRMS $(m / z)$ : $[\mathrm{M}+\mathrm{H}]^{+}$calcd. for $\mathrm{C}_{21} \mathrm{H}_{17} \mathrm{~N}_{4} \mathrm{O} 341.1402$, found 341.1389 .

\subsubsection{6. (E)-1-(1H-indol-3-yl)-3-(1-phenyl-3-(pyridin-3-yl)-1H- pyrazol-4-yl)prop-2-en-1-one (36)}

Purified by column flash chromatography $(0 \% \rightarrow 30 \%$ ethyl acetate in hexane). Yield $17 \%, \mathrm{mp} 267.5-268{ }^{\circ} \mathrm{C}$; IR (FTIR/FTNIR-ATR): $1646 \mathrm{~cm}^{-1}(\mathrm{C}=\mathrm{O}) .{ }^{1} \mathrm{H}$ NMR (DMSO-d $\left.6,400 \mathrm{MHz}\right) \delta: 12.14(1 \mathrm{H}, \mathrm{s})$, $9.33(1 \mathrm{H}, \mathrm{s}), 8.90(1 \mathrm{H}, \mathrm{d}, J=1.6 \mathrm{~Hz}), 8.71(1 \mathrm{H}, \mathrm{dd}, J=1.6, J=4.8 \mathrm{~Hz})$, $8.51(1 \mathrm{H}, \mathrm{s}), 8.30(1 \mathrm{H}, \mathrm{d}, J=6.8 \mathrm{~Hz}), 8.11(1 \mathrm{H}, \mathrm{dt}, J=2, J=8 \mathrm{~Hz}), 7.96$ $(2 \mathrm{H}, \mathrm{d}, J=7.6 \mathrm{~Hz}), 7.78(1 \mathrm{H}, \mathrm{d}, J=15.2 \mathrm{~Hz}), 7.63-7.41(6 \mathrm{H}, \mathrm{m})$, $7.27-7.20(2 \mathrm{H}, \mathrm{m}) .{ }^{13} \mathrm{C}$ NMR (DMSO- $\left.d_{6}, 400 \mathrm{MHz}\right) \delta: 183.26,149.55$, 149.52, 148.70, 138.98, 136.87, 135.70, 134.02, 129.75, 128.62, 128.19, $128.15,127.26,125.76,125.08,123.94,123.13,121.85,121.66,118.75$, 118.56, 117.64, 112.24. HRMS $(m / z):[\mathrm{M}+\mathrm{H}]^{+}$calcd. for $\mathrm{C}_{25} \mathrm{H}_{19} \mathrm{~N}_{4} \mathrm{O}$ 391.1559, found 391.1566

\subsubsection{7. (E)-1-phenyl-3-(1-phenyl-3-(pyridin-3-yl)-1H-pyrazol-4-} yl)prop-2-en-1-on [47] (37)

Purified by flash column chromatography $(0 \% \rightarrow 25 \%$ EtOAc in Hexane). Yield $30 \%, \mathrm{mp} 161-161.8^{\circ} \mathrm{C}$; IR (FTIR/FTNIR-ATR): $1664 \mathrm{~cm}^{-1}(\mathrm{C}=\mathrm{O}),{ }^{1} \mathrm{H}$ NMR $\left(\mathrm{CDCl}_{3}, 400 \mathrm{MHz}\right) \delta: 8.99(1 \mathrm{H}, \mathrm{d}$, $J=1.2 \mathrm{~Hz}), 8.69(1 \mathrm{H}, \mathrm{dd}, J=1.6 \mathrm{~Hz}, J=5.2 \mathrm{~Hz}), 8.39(1 \mathrm{H}, \mathrm{s}), 8.02(1 \mathrm{H}$, $\mathrm{dt}, J=2 \mathrm{~Hz}, J=8 \mathrm{~Hz}), 7.97-7.95(2 \mathrm{H}, \mathrm{m}), 7.83(1 \mathrm{H}, \mathrm{d}, J=15.6 \mathrm{~Hz})$, $7.79(2 \mathrm{H}, \mathrm{m}), 7.59-7.38(7 \mathrm{H}, \mathrm{m}), 7.37(1 \mathrm{H}, \mathrm{d}, J=15.6 \mathrm{~Hz}) .{ }^{13} \mathrm{C} \mathrm{NMR}$ $\left(\right.$ DMSO- $\left.d_{6}, 400 \mathrm{MHz}\right) \delta$ : 188.68, 150.05, 149.70, 148.76, 138.84,
$137.57,135.82,133.52,133.14,129.74,129.11,128.80,128.22,127.90$, $127.39,123.95,121.90,118.79,118.17$. Anal. calcd for $\mathrm{C}_{23} \mathrm{H}_{17} \mathrm{~N}_{3} \mathrm{O} \mathrm{C}$, 78.61; H, 4.88; N, 11.96. found: C, 78.77; H, 4.85; N, 11.58. HRMS ( $m /$ $z):[\mathrm{M}+\mathrm{H}]^{+}$calcd. for $\mathrm{C}_{23} \mathrm{H}_{18} \mathrm{~N}_{3} \mathrm{O}$ 352.1450; found 352.1443.

4.1.28. (E)-3-(1-phenyl-3-(pyridin-3-yl)-1H-pyrazol-4-yl)-1(3,4,5-trimethoxyphenyl)prop-2-en-1-on (CAS No: 1287408-93-8) (38)

Purified by flash column chromatography $(0 \% \rightarrow 25 \%$ EtOAc in Hexane). Yield $21 \%, \mathrm{mp} 115-116^{\circ} \mathrm{C}$; IR (FTIR/FTNIR-ATR): $1646 \mathrm{~cm}^{-1}(\mathrm{C}=\mathrm{O}),{ }^{1} \mathrm{H}$ NMR $\left(\mathrm{CDCl}_{3}\right) \delta: 8.99(1 \mathrm{H}, \mathrm{d}, J=1.2 \mathrm{~Hz}), 8.69$ $(1 \mathrm{H}, \mathrm{dd}, J=1.6 \mathrm{~Hz}, J=5.2 \mathrm{~Hz}), 8.36(1 \mathrm{H}, \mathrm{s}), 8.02(1 \mathrm{H}, \mathrm{dt}, J=2 \mathrm{~Hz}$, $J=8 \mathrm{~Hz}), 7.84(1 \mathrm{H}, \mathrm{d}, J=15.6 \mathrm{~Hz}), 7.54-7.34(6 \mathrm{H}, \mathrm{m}), 7.29(1 \mathrm{H}, \mathrm{d}$, $J=15.6 \mathrm{~Hz}$ ), $7.19(2 \mathrm{H}, \mathrm{s}), 3.92(6 \mathrm{H}, \mathrm{s}), 3.86(3 \mathrm{H}, \mathrm{s}) .{ }^{13} \mathrm{C}$ NMR (DMSO$\left.d_{6}, 400 \mathrm{MHz}\right) \delta: 187.51,152.91,149.99,149.72,148.81,142.02,138.84$, $135.88,133.36,132.95,129.75,129.24,128.01,127.44,123.96,121.82$, 118.94, 118.22, 118.14, 106.03, 60.21, 56.23. Anal. calcd for $\mathrm{C}_{26} \mathrm{H}_{23} \mathrm{~N}_{3} \mathrm{O}_{4} \mathrm{C}, 70.73 ; \mathrm{H}, 5.25 ; \mathrm{N}, 9.52$; found: C, 70.95; H, 5.53; N, 9.12. HRMS $(m / z)$ : $[\mathrm{M}+\mathrm{H}]^{+}$calcd. for $\mathrm{C}_{26} \mathrm{H}_{24} \mathrm{~N}_{3} \mathrm{O}_{4}$ 442.1767; found 442.1777

4.1.29. (E)-3-(1-phenyl-3-(pyridin-3-yl)-1H-pyrazol-4-yl)-1-

(2,4,6-trimethoxyphenyl)prop-2-en-1-on (39)

Purified by flash column chromatography $(0 \% \rightarrow 20 \%$ EtOAc in Hexane). Yield 22\%, mp 206-207 ${ }^{\circ}$; IR (FTIR/FTNIR-ATR): $1625 \mathrm{~cm}^{-1}(\mathrm{C}=0) .{ }^{1} \mathrm{H}$ NMR (DMSO- $\left.d_{6}, 400 \mathrm{MHz}\right) \delta: 9.26(1 \mathrm{H}, \mathrm{s})$, $8.73(1 \mathrm{H}, \mathrm{d}, J=2 \mathrm{~Hz}), 8.67(1 \mathrm{H}, \mathrm{dd}, J=1,6 \mathrm{~Hz}, J=4.8 \mathrm{~Hz}), 7.96-7.93$ $(3 \mathrm{H}, \mathrm{m}), 7.59-7.54(3 \mathrm{H}, \mathrm{m}), 7.42-7.38(1 \mathrm{H}, \mathrm{m}), 7.16(1 \mathrm{H}, \mathrm{d}$, $J=16 \mathrm{~Hz}), 6.86(1 \mathrm{H}, \mathrm{d}, J=16 \mathrm{~Hz}), 6.29(2 \mathrm{H}, \mathrm{s}), 3.81(3 \mathrm{H}, \mathrm{s}), 3.75(6 \mathrm{H}$, s). ${ }^{13} \mathrm{C}$ NMR (DMSO- $\left.d_{6}, 400 \mathrm{MHz}\right) \delta: 193.08,161.90,157.89,149.63$, 149.36, 148.53, 138.83, 135.46, 133.98, 129.66, 129.18, 128.92, 127.84, $127.29,123.85,118.78,117.46,110.57,90.86,55.76,55.44$. Anal. calcd for $\mathrm{C}_{26} \mathrm{H}_{23} \mathrm{~N}_{3} \mathrm{O}_{4} \mathrm{C}, 70.73 ; \mathrm{H}, 5.25 ; \mathrm{N}, 9.52$; found: C, 70.92; H, 5.38; N, 9.48. HRMS (m/z): $[\mathrm{M}+\mathrm{H}]^{+}$calcd. for $\mathrm{C}_{26} \mathrm{H}_{24} \mathrm{~N}_{3} \mathrm{O}_{4} 442.1767$; found 442.1762 .

4.1.30. (E)-3-(1-phenyl-3-(pyridin-3-yl)-1H-pyrazol-4-yl)-1-

(2,3,4-trimethoxyphenyl)prop-2-en-1-on (40)

Purified by flash column chromatography $(0 \% \rightarrow 25 \%$ EtOAc in Hexane). Yield $28 \%, \mathrm{mp} \quad 91-92^{\circ} \mathrm{C}$; IR (FTIR/FTNIR-ATR): $1648 \mathrm{~cm}^{-1}(\mathrm{C}=\mathrm{O}) .{ }^{1} \mathrm{H}$ NMR $\left(\mathrm{CDCl}_{3}, 400 \mathrm{MHz}\right) \delta: 8.98(1 \mathrm{H}, \mathrm{d}$, $J=1.6 \mathrm{~Hz}), 8.67(1 \mathrm{H}, \mathrm{dd}, J=1.6 \mathrm{~Hz}, J=5.2 \mathrm{~Hz}), 8.33(1 \mathrm{H}, \mathrm{s}), 8.02(1 \mathrm{H}$, $\mathrm{dt}, J=1.6 \mathrm{~Hz}, J=8 \mathrm{~Hz}), 7.79(2 \mathrm{H}, \mathrm{m}), 7.70(1 \mathrm{H}, \mathrm{d}, J=15.6 \mathrm{~Hz})$, $7.53-7.37(5 \mathrm{H}, \mathrm{m}), 7.33(1 \mathrm{H}, \mathrm{d}, J=15.6 \mathrm{~Hz}), 6.75(1 \mathrm{H}, \mathrm{d}, J=8.8 \mathrm{~Hz})$, $3.92(3 \mathrm{H}, \mathrm{s}), 3.91(3 \mathrm{H}, \mathrm{s}), 3.87(3 \mathrm{H}, \mathrm{s})$. Anal. calcd. for $\mathrm{C}_{26} \mathrm{H}_{23} \mathrm{~N}_{3} \mathrm{O}_{4} \mathrm{C}$, 70.73; H, 5.25; N, 9.52; found: C, 70.92; H, 5.17; N, 9.52. HRMS (m/z): $[\mathrm{M}+\mathrm{H}]^{+}$calcd. for $\mathrm{C}_{26} \mathrm{H}_{24} \mathrm{~N}_{3} \mathrm{O}_{4} 442.1767$; found 442.1765 .

4.1.31. (E)-1-(3,4-Dimethoxyphenyl)-3-(1-phenyl-3-(pyridin-3-yl)1H-pyrazol-4-yl)prop-2-en-1-on (CAS No: 1002609-04-2) (41)

Purified by flash column chromatography $(0 \% \rightarrow 25 \%$ EtOAc in Hexane). Yield $36 \%, \mathrm{mp} 162-163^{\circ} \mathrm{C}$; IR (FTIR/FTNIR-ATR): $1655 \mathrm{~cm}^{-1}(\mathrm{C}=\mathrm{O}) .{ }^{1} \mathrm{H}$ NMR $\left(\mathrm{CDCl}_{3}, 300 \mathrm{MHz}\right) \delta: 8.97(1 \mathrm{H}, \mathrm{s}), 8.65$ $(1 \mathrm{H}, \mathrm{d}, J=3.6 \mathrm{~Hz}), 8.34(1 \mathrm{H}, \mathrm{s}), 8.03(1 \mathrm{H}, \mathrm{d}, J=7.8 \mathrm{~Hz}), 7.79-7.77$ $(2 \mathrm{H}, \mathrm{m}), 7.76(1 \mathrm{H}, \mathrm{d}, J=15.9 \mathrm{~Hz}), 7.55-7.33(7 \mathrm{H}, \mathrm{m}), 6.85(1 \mathrm{H}, \mathrm{d}$, $J=7.8 \mathrm{~Hz}$ ), $3.91(6 \mathrm{H}, \mathrm{s}) .{ }^{13} \mathrm{C}$ NMR (DMSO- $\left.d_{6}, 400 \mathrm{MHz}\right) \delta: 186.85$, 153.22, 149.88, 149.66, 148.82, 148.77, 138.87, 135.81, 132.46, 130.46, $129.73,128.98,128.02,127.34,123.93,122.94,121.85,118.81,118.26$, 110.87, 110.64, 55.78, 55.57. Anal. calcd. for $\mathrm{C}_{25} \mathrm{H}_{21} \mathrm{~N}_{3} \mathrm{O}_{3} \mathrm{C}, 72.98 ; \mathrm{H}$, 5.14; N, 10.21; found: C, 72.49; $\mathrm{H}, 5.05 ; \mathrm{N}, 10.03$. HRMS $(\mathrm{m} / \mathrm{z})$ : $[\mathrm{M}+\mathrm{H}]^{+}$calcd. for $\mathrm{C}_{25} \mathrm{H}_{22} \mathrm{~N}_{3} \mathrm{O}_{3}$ 412.1661; found 412.1650 .

\subsubsection{2. (E)-1-(2,5-Dimethoxyphenyl)-3-(1-phenyl-3-(pyridin-3-yl)-} 1H-pyrazol-4-yl)prop-2-en-1-on (42)

Purified by recrystallization from hexane-ethyl acetate mixture. 
Yield 57\%, mp 129-130 ${ }^{\circ} \mathrm{C}$; IR (FTIR/FTNIR-ATR): $1656 \mathrm{~cm}^{-1}(\mathrm{C}=0)$ ). ${ }^{1} \mathrm{H}$ NMR (DMSO- $\left.d_{6}, 400 \mathrm{MHz}\right) \delta: 9.29(1 \mathrm{H}, \mathrm{s}), 8.82(1 \mathrm{H}, \mathrm{d}, J=1.6 \mathrm{~Hz})$, $8.69(1 \mathrm{H}, \mathrm{d}, J=4.8 \mathrm{~Hz}), 8.04(1 \mathrm{H}, \mathrm{d}, J=8.4 \mathrm{~Hz}), 7.96(2 \mathrm{H}, \mathrm{d}, J=8 \mathrm{~Hz})$, 7.59-7.39 (5H, m), $7.28(1 \mathrm{H}, \mathrm{d}, J=16 \mathrm{~Hz}), 7.13-7.07(2 \mathrm{H}, \mathrm{m}), 7.02$ $(1 \mathrm{H}, \mathrm{s}), 3.80(3 \mathrm{H}, \mathrm{s}), 3.74(3 \mathrm{H}, \mathrm{s}) .{ }^{13} \mathrm{C}$ NMR (DMSO- $\left.d_{6}, 400 \mathrm{MHz}\right) \delta$ : 191.72, 152.99, 151.50, 149.74, 149.68, 148.72, 138.81, 135.77, 133.13, $129.66,129.21,129.18,127.98,127.32,126.64,123.86,118.85,118.19$, $117.80,113.94,113.59,56.25,55.53$. Anal. calcd for $\mathrm{C}_{25} \mathrm{H}_{21} \mathrm{~N}_{3} \mathrm{O}_{3} \mathrm{C}$, 72.98; H, 5.14; N, 10.21; found: C, 73.31; H, 5.57; N, 10.40. HRMS ( $m /$ $z)$ : $[\mathrm{M}+\mathrm{H}]^{+}$calcd. for $\mathrm{C}_{25} \mathrm{H}_{22} \mathrm{~N}_{3} \mathrm{O}_{3}$ 412.1661; found 412.1649 .

4.1.33. (E)-1-(2,4-Dimethoxyphenyl)-3-(1-phenyl-3-(pyridin-3-yl)1H-pyrazol-4-yl)prop-2-en-1-on (CAS No: 1002461-21-3) (43)

Purified by recrystallization from acetone-water mixture. Yield 34\%, mp 130-131 ${ }^{\circ} \mathrm{C}$; IR (FTIR/FTNIR-ATR): $1646 \mathrm{~cm}^{-1}(\mathrm{C}=\mathrm{O}) .{ }^{1} \mathrm{H}$ $\operatorname{NMR}\left(\mathrm{CDCl}_{3}, 300 \mathrm{MHz}\right) \delta: 9.01(1 \mathrm{H}, \mathrm{s}), 8.63(1 \mathrm{H}, \mathrm{d}, J=3.4 \mathrm{~Hz}), 8.24$ $(1 \mathrm{H}, \mathrm{s}), 8.20(1 \mathrm{H}, \mathrm{d}, J=7.2 \mathrm{~Hz}), 7.73-7.68(2 \mathrm{H}, \mathrm{m}), 7.62(1 \mathrm{H}, \mathrm{d}$, $J=15.6 \mathrm{~Hz}), 7.55-7.53(2 \mathrm{H}, \mathrm{m}), 7.46(1 \mathrm{H}, \mathrm{t}, J=7.8 \mathrm{~Hz}), 7.34-7.32$ $(1 \mathrm{H}, \mathrm{m}), 7.31(1 \mathrm{H}, \mathrm{d}, J=15.6 \mathrm{~Hz}), 6.52(1 \mathrm{H}, \mathrm{d}, J=8.7 \mathrm{~Hz}), 6.43(1 \mathrm{H}, \mathrm{d}$, $J=1.8 \mathrm{~Hz}$ ), $3.81(6 \mathrm{H}, \mathrm{s}) .{ }^{13} \mathrm{C}$ NMR (DMSO-d, $\left.400 \mathrm{MHz}\right) \delta: 189.16$, 163.83, 159.99, 149.61, 148.78, 138.87, 135.84, 131.96, 131.27, 129.64, 129.00, 128.16, 127.24, 126.88, 123.88, 121.28, 118.87, 118.10, 105.89, $98.50,55.88,55.57$. Anal. calcd. for $\mathrm{C}_{25} \mathrm{H}_{21} \mathrm{~N}_{3} \mathrm{O}_{3} \mathrm{C}, 72.98 ; \mathrm{H}, 5.14 ; \mathrm{N}$, 10.21; found: C, 73.33; H, 5.38; N, 10.21. HRMS (m/z): $[\mathrm{M}+\mathrm{H}]^{+}$calcd. for $\mathrm{C}_{25} \mathrm{H}_{22} \mathrm{~N}_{3} \mathrm{O}_{3} 412.1661$; found 412.1643 .

4.1.34. (E)-3-(1-phenyl-3-(pyridin-4-yl)-1H-pyrazol-4-yl)-1(thiophen-3-yl)prop-2-en-1-one (44)

Purified by column flash chromatography $(0 \% \rightarrow 50 \%$ ethyl acetate in hexane) then by recrystallization of ethyl acetate and hexane. Yield 54\%, mp $219-220^{\circ} \mathrm{C}$; IR (FTIR/FTNIR-ATR): $1655 \mathrm{~cm}^{-1}(\mathrm{C}=\mathrm{O}) .{ }^{1} \mathrm{H}$ NMR $\left(\mathrm{CDCl}_{3}, 400 \mathrm{MHz}\right) \delta: 8.74(2 \mathrm{H}, \mathrm{d}$, $J=6 \mathrm{~Hz}), 8.36(1 \mathrm{H}, \mathrm{s}), 8.08(1 \mathrm{H}, \mathrm{d}, J=2.8 \mathrm{~Hz}), 7.90(1 \mathrm{H}, \mathrm{d}$, $J=15.6 \mathrm{~Hz}), 7.79(2 \mathrm{H}, \mathrm{d}, J=7.6 \mathrm{~Hz}), 7.67-7.62(3 \mathrm{H}, \mathrm{m}), 7.52(2 \mathrm{H}, \mathrm{t}$, $J=8 \mathrm{~Hz}), 7.41-7.36(2 \mathrm{H}, \mathrm{m}), 7.26(1 \mathrm{H}, \mathrm{d}, J=15.6 \mathrm{~Hz}) .{ }^{13} \mathrm{C} \mathrm{NMR}$ (DMSO- $\left.d_{6}, 400 \mathrm{MHz}\right) \delta: 182.68,150.26,149.94,142.76,139.28$, $138.76,133.55,132.13,129.75,129.15,127.84,127.53,126.91,123.74$, 122.61, 118.88, 118.30. HRMS (m/z): $[\mathrm{M}+\mathrm{H}]^{+}$calcd. for $\mathrm{C}_{21} \mathrm{H}_{16} \mathrm{~N}_{3} \mathrm{OS}$ 358.1014, found 358.1008.

4.1.35. (E)-1-(benzo[d][1,3]dioxol-5-yl)-3-(1-phenyl-3-(pyridin-4yl)-1H-pyrazol-4-yl)prop-2-en-1-one (45)

Purified by column flash chromatography $(0 \% \rightarrow 50 \%$ ethyl acetate in hexane). Yield $60 \%, \mathrm{mp} 148.2-148.8^{\circ} \mathrm{C}$; IR (FTIR/FTNIRATR): $1656 \mathrm{~cm}^{-1}(\mathrm{C}=\mathrm{O}) .{ }^{1} \mathrm{H}$ NMR $\left(\mathrm{CDCl}_{3}, 400 \mathrm{MHz}\right) \delta: 8.73(2 \mathrm{H}, \mathrm{d}$, $J=5.6 \mathrm{~Hz}), 8.36(1 \mathrm{H}, \mathrm{s}), 7.87(1 \mathrm{H}, \mathrm{d}, J=15.2 \mathrm{~Hz}), 7.80(2 \mathrm{H}, \mathrm{d}$, $J=7.6 \mathrm{~Hz}), 7.66(2 \mathrm{H}, \mathrm{d}, J=6 \mathrm{~Hz}), 7.59-7.50(4 \mathrm{H}, \mathrm{m}), 7.38-7.34(2 \mathrm{H}$, $\mathrm{m}), 6.88(1 \mathrm{H}, \mathrm{d}, J=8.4 \mathrm{~Hz}), 6.06(2 \mathrm{H}, \mathrm{s}) .{ }^{13} \mathrm{C}$ NMR (DMSO-d, $400 \mathrm{MHz}$ ) $\delta: 186.37,151.47,150.17,149.85,147.95,139.27,138.73$, 132.41, 132.14, 129.63, 129.13, 127.40, 124.57, 122.52, 122.25, 118.79, 118.36, 108.07, 107.60, 102.03. HRMS $(\mathrm{m} / \mathrm{z})$ : $[\mathrm{M}+\mathrm{H}]^{+}$calcd. for $\mathrm{C}_{24} \mathrm{H}_{18} \mathrm{~N}_{3} \mathrm{O}_{3}$ 396.1348, found 396.1338.

4.1.36. (E)-3-(1-phenyl-3-(pyridin-4-yl)-1H-pyrazol-4-yl)-1-(1Hpyrrol-3-yl)prop-2-en-1-one (46)

Purified by column flash chromatography $(0 \% \rightarrow 6 \%$ methanol in dichloromethane). Yield $28 \%, \mathrm{mp} 258-258.6^{\circ} \mathrm{C}$; IR (FTIR/FTNIRATR): $1645 \mathrm{~cm}^{-1}(\mathrm{C}=\mathrm{O}) .{ }^{1} \mathrm{H} \mathrm{NMR}\left(\mathrm{CDCl}_{3}, 400 \mathrm{MHz}\right) \delta$ : $9.62(1 \mathrm{H}, \mathrm{bs})$, $8.74(2 \mathrm{H}, \mathrm{d}, J=4.2 \mathrm{~Hz}), 8.35(1 \mathrm{H}, \mathrm{s}), 7.87(1 \mathrm{H}, \mathrm{d}, J=15.6 \mathrm{~Hz}), 7.80$ $(2 \mathrm{H}, \mathrm{d}, J=7.6 \mathrm{~Hz}), 7.67(2 \mathrm{H}, \mathrm{d}, J=4.4 \mathrm{~Hz}), 7.53(2 \mathrm{H}, \mathrm{t}, J=8 \mathrm{~Hz})$, $7.40-7.36(1 \mathrm{H}, \mathrm{m}), 7.20(1 \mathrm{H}, \mathrm{d}, J=15.6 \mathrm{~Hz}), 7.10(1 \mathrm{H}, \mathrm{s}), 6.96(1 \mathrm{H}, \mathrm{m})$, 6.35-6.33 $(1 \mathrm{H}, \mathrm{m}) .{ }^{13} \mathrm{C}$ NMR (DMSO- $\left.d_{6}, 400 \mathrm{MHz}\right) \delta: 177.44,150.25$, 149.65, 139.51, 138.83, 132.93, 129.72, 129.54, 128.85, 127.41, 126.45, $123.83,122.64,118.83,118.49,116.89,110.07$. HRMS $(m / z):[\mathrm{M}+\mathrm{H}]^{+}$ calcd. for $\mathrm{C}_{21} \mathrm{H}_{17} \mathrm{~N}_{4} \mathrm{O} 341.1402$, found 341.1400.
4.1.37. (E)-1-phenyl-3-(1-phenyl-3-(pyridin-4-yl)-1H-pyrazol-4yl)prop-2-en-1-one (CAS No:1390831-45-4) (47)

Purified by flash column chromatography $(0 \% \rightarrow 25 \%$ EtOAc in Hexane). Yield 36\%, mp 215-216 ${ }^{\circ} \mathrm{C}$; IR (FTIR/FTNIR-ATR): $1656 \mathrm{~cm}^{-1}(\mathrm{C}=\mathrm{O}) .{ }^{1} \mathrm{H}$ NMR $\left(\mathrm{CDCl}_{3}, 300 \mathrm{MHz}\right) \delta: 8.70(2 \mathrm{H}, \mathrm{d}$, $J=4.5 \mathrm{~Hz}), 8.37(1 \mathrm{H}, \mathrm{s}), 7.96(2 \mathrm{H}, \mathrm{d}, J=7.5 \mathrm{~Hz}), 7.86(2 \mathrm{H}, \mathrm{d}$, $J=15.6 \mathrm{~Hz}), 7.78-7.69(2 \mathrm{H}, \mathrm{m}), 7.58-7.36(3 \mathrm{H}, \mathrm{m}), 7.58-7.36(4 \mathrm{H}$, $\mathrm{m}), 7.22-7.20(1 \mathrm{H}, \mathrm{m}) .{ }^{13} \mathrm{C}$ NMR (DMSO- $\left.d_{6}, 400 \mathrm{MHz}\right) \delta: 188.66$, $150.27, \quad 150.07, \quad 139.27,138.76,137.52,133.24,133.14$, $129.74,129.35,128.20,128.24,127.52,122.65,122.32,118.85,118.32$. Anal. calcd. for $\mathrm{C}_{23} \mathrm{H}_{17} \mathrm{~N}_{3} \mathrm{O}$ C, 78.61; $\mathrm{H}, 4.88 ; \mathrm{N}, 11.96$. found $\mathrm{C}, 78.25$; $\mathrm{H}, 4.85 ; \mathrm{N}, 11.82$. HRMS $(\mathrm{m} / \mathrm{z})$ : $[\mathrm{M}+\mathrm{H}]^{+}$calcd. for $\mathrm{C}_{23} \mathrm{H}_{18} \mathrm{~N}_{3} \mathrm{O}$ 352.1450; found 352.1447.

4.1.38. (E)-3-(1-phenyl-3-(pyridin-4-yl)-1H-pyrazol-4-yl)-1(3,4,5-trimethoxyphenyl)prop-2-en-1-on (CAS No: 1390911-60-0) (48)

Purified by flash column chromatography $(0 \% \rightarrow 25 \%$ EtOAc in Hexane). Yield 18\%, mp $161-162^{\circ} \mathrm{C}$; IR (FTIR/FTNIR-ATR): $1656 \mathrm{~cm}^{-1}(\mathrm{C}=\mathrm{O}) .{ }^{1} \mathrm{H}$ NMR $\left(\mathrm{CDCl}_{3}, 300 \mathrm{MHz}\right) \delta: 8.67(2 \mathrm{H}, \mathrm{bs}), 8.34$ $(1 \mathrm{H}, \mathrm{s}), 7.84(1 \mathrm{H}, \mathrm{d}, J=15.6 \mathrm{~Hz}), 7.75-7.70(4 \mathrm{H}, \mathrm{m}), 7.49-7.36(3 \mathrm{H}$, m), $7.33(1 \mathrm{H}, \mathrm{d}, J=15.6 \mathrm{~Hz}), 7.16(2 \mathrm{H}, \mathrm{s}), 3.87(9 \mathrm{H}, \mathrm{s}) .{ }^{13} \mathrm{C} \mathrm{NMR}$ $\left(\mathrm{DMSO}-d_{6}, 400 \mathrm{MHz}\right) \delta$ : 187.40, 152.91, 150.27, 150.05, 142.08, $139.40,138.76,133.03,132.90,129.76,129.44,127.56,122.72,122.22$, 119.02, 118.30, 106.08, 60.21, 59.72, 56.23. Anal. calcd. for $\mathrm{C}_{26} \mathrm{H}_{23} \mathrm{~N}_{3} \mathrm{O}_{4} \mathrm{C}, 70.73 ; \mathrm{H}, 5.25 ; \mathrm{N}, 9.52$. found $\mathrm{C}, 70.34 ; \mathrm{H}, 5.63 ; \mathrm{N}$, 9.65. HRMS (m/z): $[\mathrm{M}+\mathrm{H}]^{+}$calcd. for $\mathrm{C}_{26} \mathrm{H}_{24} \mathrm{~N}_{3} \mathrm{O}_{4} 442.1767$; found 442.1757.

\subsubsection{9. (E)-3-(1-phenyl-3-(pyridin-4-yl)-1H-pyrazol-4-yl)-1-}

(2,4,6-trimethoxyphenyl)prop-2-en-1-on (49)

Purified by recrystallization from ethanol-water mixture. Yield 68\%, mp 192-193 ${ }^{\circ} \mathrm{C}$; IR (FTIR/FTNIR-ATR): $1636 \mathrm{~cm}^{-1}$ (C=O). ${ }^{1} \mathrm{H}$ NMR (DMSO- $\left.d_{6}, 400 \mathrm{MHz}\right) \delta: 9.26(1 \mathrm{H}, \mathrm{s}), 8.71(2 \mathrm{H}, \mathrm{d}, J=6 \mathrm{~Hz}), 7.94$ $(2 \mathrm{H}, \mathrm{d}, J=8 \mathrm{~Hz}), 7.57(2 \mathrm{H}, \mathrm{t}, J=8 \mathrm{~Hz}), 7.52(2 \mathrm{H}, \mathrm{d}, J=5.6 \mathrm{~Hz})$, $7.43-7.40(1 \mathrm{H}, \mathrm{m}), 7.21(1 \mathrm{H}, \mathrm{d}, J=16 \mathrm{~Hz}), 6.89(1 \mathrm{H}, \mathrm{d}, J=16 \mathrm{~Hz})$, $6.33(2 \mathrm{H}, \mathrm{s}), 3.83(3 \mathrm{H}, \mathrm{s}), 3.75(6 \mathrm{H}, \mathrm{s}) .{ }^{13} \mathrm{C}$ NMR (DMSO- $\left.d_{6}, 400 \mathrm{MHz}\right)$ $\delta: 193.13,161.97,157.89,150.16,149.48,139.21,138.76,133.82$, 129.68, 129.51, 129.11, 127.43, 122.39, 118.87, 117.66, 110.54, 90.89, 55.79, 55.74. Anal. calcd. for $\mathrm{C}_{26} \mathrm{H}_{23} \mathrm{~N}_{3} \mathrm{O}_{4} \mathrm{C}, 70.73 ; \mathrm{H}, 5.25 ; \mathrm{N}, 9.52$. found: C, 70.42; $\mathrm{H}, 5.36 ; \mathrm{N}, 9.41$. HRMS $(\mathrm{m} / \mathrm{z}):[\mathrm{M}+\mathrm{H}]^{+}$calcd. for $\mathrm{C}_{26} \mathrm{H}_{24} \mathrm{~N}_{3} \mathrm{O}_{4}$ 442.1767; found 442.1758 .

\subsubsection{0. (E)-3-(1-phenyl-3-(pyridin-4-yl)-1H-pyrazol-4-yl)-1-}

\section{(2,3,4-trimethoxphenyl)prop-2-en-1-on (50)}

Purified by flash column chromatography $(0 \% \rightarrow 25 \%$ EtOAc in Hexane). Yield $30 \%$, mp $160-161^{\circ} \mathrm{C}$; IR (FTIR/FTNIR-ATR): $1654 \mathrm{~cm}^{-1}(\mathrm{C}=0) .{ }^{1} \mathrm{H}$ NMR $\left(\mathrm{CDCl}_{3}, 300 \mathrm{MHz}\right) \delta: 8.66(2 \mathrm{H}, \mathrm{d}$, $J=6 \mathrm{~Hz}), 8.27(1 \mathrm{H}, \mathrm{s}), 7.74-7.68(5 \mathrm{H}, \mathrm{m}), 7.48-7.35(4 \mathrm{H}, \mathrm{m}), 7.33$ $(1 \mathrm{H}, \mathrm{d}, J=15.6 \mathrm{~Hz}), 6.70(1 \mathrm{H}, \mathrm{d}, J=8.7 \mathrm{~Hz}), 3.87(3 \mathrm{H}, \mathrm{s}), 3.86(3 \mathrm{H}, \mathrm{s})$, $3.83(3 \mathrm{H}, \mathrm{s}) .{ }^{13} \mathrm{C}$ NMR (DMSO- $\left.d_{6}, 400 \mathrm{MHz}\right) \delta: 189.76,156.56,152.75$, 150.22, 149.87, 141.65, 139.40, 138.77, 132.28, 129.67, 129.15, 127.45, 126.71, 126.11, 125.07, 122.69, 118.95, 118.10, 107.88, 61.83, 60.53, 56.08. Anal. calcd. for $\mathrm{C}_{26} \mathrm{H}_{23} \mathrm{~N}_{3} \mathrm{O}_{4} \mathrm{C}, 70.73 ; \mathrm{H}, 5.25 ; \mathrm{N}$, 9.52. found: $\mathrm{C}$, 70.47; H, 5.12; N, 9.37. HRMS (m/z): $[\mathrm{M}+\mathrm{H}]^{+}$calcd. for $\mathrm{C}_{26} \mathrm{H}_{24} \mathrm{~N}_{3} \mathrm{O}_{4}$ 442.1767; found 442.1781.

4.1.41. (E)-1-(3,4-Dimethoxyphenyl)-3-(1-phenyl-3-(pyridin-4-yl)1H-pyrazol-4-yl)prop-2-en-1-on (CAS No: 1147371-58-1) (51)

Purified by recrystallization from acetone-water mixture. Yield 44\%, mp 190-191 ${ }^{\circ} \mathrm{C}$; IR (FTIR/FTNIR-ATR): $1653 \mathrm{~cm}^{-1}(\mathrm{C}=\mathrm{O}) .{ }^{1} \mathrm{H}$ $\operatorname{NMR}\left(\mathrm{CDCl}_{3}, 300 \mathrm{MHz}\right) \delta: 8.68(2 \mathrm{H}, \mathrm{bs}), 8.34(1 \mathrm{H}, \mathrm{s}), 7.83(1 \mathrm{H}, \mathrm{d}$, $J=15.6 \mathrm{~Hz}), 7.76-7.69(4 \mathrm{H}, \mathrm{m}), 7.55-7.20(5 \mathrm{H}, \mathrm{m}), 6.87(1 \mathrm{H}, \mathrm{d}$, $J=9 \mathrm{~Hz}$ ), $3.92(3 \mathrm{H}, \mathrm{s}), 3.91(3 \mathrm{H}, \mathrm{s}) .{ }^{13} \mathrm{C}$ NMR (DMSO- $\left.d_{6}, 400 \mathrm{MHz}\right) \delta$ : 186.83, 153.26, 150.26, 149.93, 148.84, 139.40, 138.80, 132.18, 130.43, 
$129.74,129.24,127.49,123.02,122.67,122.30,118.90,118.43,110.87$, $110.65,55.80,55.58$. Anal. calcd for $\mathrm{C}_{25} \mathrm{H}_{21} \mathrm{~N}_{3} \mathrm{O}_{3} \mathrm{C}, 72.98 ; \mathrm{H}, 5.14 ; \mathrm{N}$, 10.21. found: C, 72.58; $\mathrm{H}, 5.12 ; \mathrm{N}, 10.05$. HRMS (m/z): $[\mathrm{M}+\mathrm{H}]^{+}$calcd. for $\mathrm{C}_{25} \mathrm{H}_{22} \mathrm{~N}_{3} \mathrm{O}_{3}$ 412.1661; found 412.1651 .

\subsubsection{2. (E)-1-(2,5-Dimethoxyphenyl)-3-(1-phenyl-3-(pyridin-4-yl)-} 1H-pyrazol-4-yl)prop-2-en-1-on (52)

Purified by recrystallization from acetone-water mixture. Yield 32\%, mp 136-137 ${ }^{\circ}$; IR (FTIR/FTNIR-ATR): $1656 \mathrm{~cm}^{-1}$ (C=0). ${ }^{1} \mathrm{H}$ NMR (DMSO- $\left.d_{6}, 400 \mathrm{MHz}\right) \delta: 9.30(1 \mathrm{H}, \mathrm{s}), 8.73(2 \mathrm{H}, \mathrm{d}, J=5.2 \mathrm{~Hz})$, $7.96(2 \mathrm{H}, \mathrm{d}, J=8 \mathrm{~Hz}), 7.63(2 \mathrm{H}, \mathrm{d}, J=6 \mathrm{~Hz}), 7.60-7.56(2 \mathrm{H}, \mathrm{m}), 7.50$ $(1 \mathrm{H}, \mathrm{d}, J=16 \mathrm{~Hz}), 7.44-7.40(1 \mathrm{H}, \mathrm{m}), 7.32(1 \mathrm{H}, \mathrm{d}, J=16 \mathrm{~Hz})$, 7.15-7.09 (2H, m), $7.04(1 \mathrm{H}, \mathrm{d}, J=2.8 \mathrm{~Hz}), 3.81(3 \mathrm{H}, \mathrm{s}), 3.75(3 \mathrm{H}, \mathrm{s})$. ${ }^{13} \mathrm{C}$ NMR (DMSO- $\left.d_{6}, 400 \mathrm{MHz}\right) \delta: 191.69,153.01,151.56,150.14$, 149.86, 139.43, 138.75, 132.83, 129.68, 129.33, 129.21, 127.47, 127.07, $122.68,118.95,118.19,117.98,114.01,113.65,56.30,55.55$. Anal. calcd. for $\mathrm{C}_{25} \mathrm{H}_{21} \mathrm{~N}_{3} \mathrm{O}_{3} \mathrm{C}, 72.98 ; \mathrm{H}, 5.14 ; \mathrm{N}, 10.21$. found: $\mathrm{C}, 72.87 ; \mathrm{H}$, 5.12; N, 9.88. HRMS $(m / z):[\mathrm{M}+\mathrm{H}]^{+}$calcd. for $\mathrm{C}_{25} \mathrm{H}_{22} \mathrm{~N}_{3} \mathrm{O}_{3} 412.1661$; found 412.1641 .

\subsubsection{3. (E)-1-(2,4-Dimethoxyphenyl)-3-(1-phenyl-3-(pyridin-4-yl)-} 1H-pyrazol-4-yl)prop-2-en-1-on (CAS No: 1147368-37-3) (53)

Purified by recrystallization from acetone-water mixture. Yield $36 \%, \mathrm{mp} 182-183^{\circ} \mathrm{C}$; IR (FTIR/FTNIR-ATR): $1644 \mathrm{~cm}^{-1}(\mathrm{C}=0) .{ }^{1} \mathrm{H}$ NMR $\left(\mathrm{CDCl}_{3}, 300 \mathrm{MHz}\right) \delta: 8.66(2 \mathrm{H}, \mathrm{d}, J=4.5 \mathrm{~Hz}), 8.22(1 \mathrm{H}, \mathrm{s})$, 7.73-7.67 (6H, m), 7.48-7.43 $(2 \mathrm{H}, \mathrm{m}), 7.37-7.32(2 \mathrm{H}, \mathrm{m}), 6.50(1 \mathrm{H}$, $\mathrm{dd}, J=2.1 \mathrm{~Hz}, J=8.7 \mathrm{~Hz}), 6.42(1 \mathrm{H}, \mathrm{d}, J=2.4 \mathrm{~Hz}), 3.80(3 \mathrm{H}, \mathrm{s}), 3.79$ (3H, s). Anal. calcd for $\mathrm{C}_{25} \mathrm{H}_{21} \mathrm{~N}_{3} \mathrm{O}_{3} \mathrm{C}, 72.98 ; \mathrm{H}, 5.14 ; \mathrm{N}, 10.21$. found: $\mathrm{C}, 72.67 ; \mathrm{H}, 5.12 ; \mathrm{N}, 9.98$. HRMS $(\mathrm{m} / \mathrm{z}):[\mathrm{M}+\mathrm{H}]^{+}$calcd. for $\mathrm{C}_{25} \mathrm{H}_{22} \mathrm{~N}_{3} \mathrm{O}_{3}$ 412.1661; found 412.1642 .

\subsection{Biological evaluation}

\subsubsection{Cells culture}

Hepatocellular carcinoma cell lines (Huh7, HepG2 and Mahlavu), human breast carcinoma cells (MCF7) and human colon carcinma cells (HCT116) were grown in Dulbecco's Modified Eagles Medium (DMEM) supplemented with $10 \%$ fetal bovine serum (Invitrogen GIBCO), 1\% non-essential amino acids (GIBCO, Invitrogen) and SNU-475 were grown in RPMI-1640 media (Invitrogen GIBCO) supplemented with 10\% FBS, 2 mM L-glutamine. MCF12A, human breast epithelial cells, were grown in DMEM/HAMS F12 media (Invitrogen GIBCO) supplemented with 10\% FBS, 1\% NEAA, $100 \mathrm{ng} / \mathrm{ml}$ EGF, $500 \mathrm{ng} / \mathrm{ml}$ hydrocortisone, and $10 \mu \mathrm{g} / \mathrm{ml}$ insulin. MRC-5, human fetal lung fibroblast cells, were maintained in Minimum Essential Medium (MEM) (Invitrogen GIBCO), with 10\% fetal bovine serum (FBS), 2 mM L-glutamine. All media contained 100 units/ml penicillin and streptomycin and cells were maintained at $37{ }^{\circ} \mathrm{C}$ in a humidified incubator under $5 \% \mathrm{CO}_{2}$.

\subsubsection{NCI-60 sulforhodamine B assay}

Cells were plated in 96-well plates (2000-3000 cell/well in 150 $\mu \mathrm{l} /$ well) and grown for $24 \mathrm{~h}$ at $37{ }^{\circ} \mathrm{C}$. Treatment of cells with the compounds (dissolved in DMSO) was done in a concentration range of $40 \mu \mathrm{M}-0.3 \mu \mathrm{M}$ (in triplicates). After $72 \mathrm{~h}$ of incubation, cells were fixed with $10 \%(\mathrm{v} / \mathrm{v})$ trichloroacetic acid (MERCK) for an hour and stained with sulforhodamine B (SRB) solution $(50 \mu \mathrm{l}$ of a $0.4 \%(\mathrm{~m} / \mathrm{v})$ of SRB in $1 \%$ acetic acid solution). For the removal of unbound SRB, cells were washed with $1 \%$ acetic acid and left for air-drying. Protein bound SRB was solubilized in $10 \mathrm{mM}$ Tris-base prior to absorbance measurement $(515 \mathrm{~nm})$ using 96-well plate reader. Cells treated with DMSO alone were used as controls for percent inhibition and $\mathrm{IC}_{50}$ calculations.
4.2.3. Real-time cell growth surveillance by electronic sensing (RTCES)

Real-time cell growth was monitored using the xCELLigence System (Roche Applied Sciences). Human cancer cell lines (1000-3000 cells/well) were seeded into 96-well E-plates. The proliferation of cells were monitored every 30 min for $24 \mathrm{~h}$ after seeding, (when cells were in log growth phase) treatments with the compounds were done. The cell index $(\mathrm{CI})$ values were recorded every $10 \mathrm{~min}$ for the first $24 \mathrm{~h}$ and then every $30 \mathrm{~min}$ for the remaining $48 \mathrm{~h}$. The cell growth ratios were calculated by $\mathrm{Cl}_{\mathrm{drug}} /$ Cl

\subsubsection{Detection of apoptosis}

Cells were seeded onto coverslips in 6-well plates. After $24 \mathrm{~h}$ in culture, cells were treated with the compounds with their $\mathrm{IC}_{50}$ concentrations. After $48 \mathrm{~h}$, apoptotic cells were identified by Annexin-V-Fluos (Roche) and DAPI (Santa Cruz) staining according to the manufacturer's recommendations (Roche). Cells were then analyzed using the fluorescence microscope (Nikon Eclipse 50i).

\subsubsection{Flow cytometry for cell cycle analysis}

Cells were seeded onto $100 \mathrm{~mm}$ culture dishes. After $24 \mathrm{~h}$, cells were treated with the compounds with their $\mathrm{IC}_{100}$ concentrations. Cells were fixed with ice-cold $70 \%$ ethanol for $3 \mathrm{~h}$ at $-20{ }^{\circ} \mathrm{C}$ after $24 \mathrm{~h}, 48 \mathrm{~h}$ and $72 \mathrm{~h}$ of incubation. Cell cycle analysis was carried out by PI (Propidium Iodide) staining using MUSE Cell Analyzer according to the manufacturer's recommendations (Millipore).

\subsubsection{Western blot analysis}

Human cancer cell lines were treated with the compounds $\left(\mathrm{IC}_{100}\right.$ concentrations) or with DMSO control for 24 h. Novex ${ }^{\circledR}$ NuPAGE $^{\circledR}$ Bis-Tris Electrophoresis system was used according to the manufacturer's protocol for all the western blotting analysis. For gel electrophoresis (NuPAGE), 20-50 $\mu$ g of protein was used per well. Then the proteins were transferred to nitrocellulose membrane via XCell IITM Blot Module. Cyclin-B1 (\#554177, BD), Cdc2/Cdk1 (\#PC25, Calbiochem), phospho-Cyclin-B1 (Ser147) (bs-3122R, Bioss), p21/WAF1/Cip1 (\#05-345, Millipore), p53 (\#05-224, Millipore), phospho-p53 (Ser15) (\#9286S, Cell Signaling), Rb (\#sc102, Santa Cruz), and phospho-Rb (Ser807/811) (\#9308S Cell Signaling) antibodies were used in 1:200 to 1:500 5\% BSA-TBS-T. $\beta$-actin (\#A5441, Sigma) antibody was used for equal loading.

\section{Author contributions}

S.N.B designed the compounds and their synthesis. M.M.H and F.E performed the chemical synthesis and characterized the compounds. S.N.B and M.M.H contributed to the writing of the manuscript. R.C.A and D.C.K designed the biological experiments and contributed to the writing of the manuscript. D.C.K performed the experiments for biological evaluation of the compounds on HCC cell lines. All authors have given approval to the final version of the manuscript.

\section{Acknowledgment}

This research was supported by Scientific Research Grants Gazi University BAP \#02/2012-41, TUBITAK \#113S540. We thank Can Justin Kiessling for the language editing and proofreading of this manuscript.

\section{Appendix A. Supplementary data}

Supplementary data associated with this article can be found in the online version, at http://dx.doi.org/10.1016/j.ejmech.2017.02. 


\section{These data include MOL files and InChiKeys of the most important compounds described in this article.}

\section{References}

[1] B.W. Stewart, C. Wild, International Agency for Research on Cancer, World Health Organization, 2014. World cancer report.

[2] G. Baffy, E.M. Brunt, S.H. Caldwell, Hepatocellular carcinoma in non-alcoholic fatty liver disease: an emerging menace, J. Hepatol. 56 (2012) 1384-1391.

[3] B. Sun, M. Karin, Obesity, inflammation, and liver cancer, J. Hepatol. 56 (2012) $704-713$.

[4] D.H. Palmer, Sorafenib in advanced hepatocellular carcinoma, N. Engl. J. Med. 359 (2008) 2498-2499.

[5] T. Ersahin, M. Ozturk, R. Cetin-Atalay, Molecular biology of liver cancer, Rev. Cell Biol. Mol. Med. 1 (2015) 206-243.

[6] N. Ozturk, E. Erdal, M. Mumcuoglu, K.C. Akcali, O. Yalcin, S. Senturk, A. ArslanErgul, B. Gur, I. Yulug, R. Cetin-Atalay, C. Yakicier, T. Yagci, M. Tez, M. Ozturk, Reprogramming of replicative senescence in hepatocellular carcinomaderived cells, PNAS 103 (2006) 2178-2183.

[7] Z. Duan, J. Zhang, E. Choy, D. Harmon, X. Liu, P. Nielsen, H. Mankin, N.S. Gray, F.J. Hornicek, Systematic kinome shRNA screening identifies CDK11 (PITSLRE) kinase expression is critical for osteosarcoma cell growth and proliferation, Clin. Cancer Res. 18 (2012) 4580-4588.

[8] B. Jia, E. Choy, G. Cote, D. Harmon, S. Ye, Q. Kan, H. Mankin, F. Hornicek, Z. Duan, Cyclin-dependent kinase 11 (CDK11) is crucial in the growth of liposarcoma cells, Cancer Lett. 342 (2014) 104-112.

[9] M.D. Garrett, A. Fattaey, CDK inhibition and cancer therapy, Curr. Opin. Genet. Dev. 9 (1999) 104-111.

[10] P.M. Fischer, D.P. Lane, Inhibitors of cyclin-dependent kinases as anti-cancer therapeutics, Curr. Med. Chem. 7 (2000) 1213-1245.

[11] C. Benson, S. Kaye, P. Workman, M. Garrett, M. Walton, J. de Bono, Clinical anticancer drug development: targeting the cyclin-dependent kinases, Br, J. Cancer 92 (2005) 7-12.

[12] G.I. Shapiro, Cyclin-dependent kinase pathways as targets for cancer treatment, J. Clin. Oncol. 24 (2006) 1770-1783.

[13] D.A. Heathcote, H. Patel, S.H. Kroll, P. Hazel, M. Periyasamy, M. Alikian, S.K. Kanneganti, A.S. Jogalekar, B. Scheiper, M. Barbazanges, A. Blum, J. Brackow, A. Siwicka, R.D. Pace, M.J. Fuchter, J.P. Snyder, D.C. Liotta, P.S. Freemont, E.O. Aboagye, R.C. Coombes, A.G. Barrett, S. Ali, A novel pyrazolo[1,5-a]pyrimidine is a potent inhibitor of cyclin-dependent protein kinases 1,2 , and 9 , which demonstrates antitumor effects in human tumor xenografts following oral administration, J. Med. Chem. 53 (2010) 8508-8522.

[14] K.F. Byth, A. Thomas, G. Hughes, C. Forder, A. McGregor, C. Geh, S. Oakes, C. Green, M. Walker, N. Newcombe, S. Green, J. Growcott, A. Barker, R.W. Wilkinson, AZD5438, a potent oral inhibitor of cyclin-dependent kinases $1,2,9$, leads to pharmacodynamic changes potent antitumor effects human tumor xenografts, Mol. Cancer Ther. 8 (2009) 1856-1866.

[15] E.X. Chen, S. Hotte, H. Hirte, L.L. Siu, J. Lyons, M. Squires, S. Lovell, S. Turner, L. McIntosh, L. Seymour, A Phase I study of cyclin-dependent kinase inhibitor, AT7519, in patients with advanced cancer: NCIC Clinical Trials Group IND 177, Br. J. Cancer 111 (2014) 2262-2267.

[16] D. Parry, T. Guzi, F. Shanahan, N. Davis, D. Prabhavalkar, D. Wiswell, W. Seghezzi, K. Paruch, M.P. Dwyer, R. Doll, A. Nomeir, W. Windsor, T. Fischmann, Y. Wang, M. Oft, T. Chen, P. Kirschmeier, E.M. Lees, Dinaciclib (SCH 727965), a novel and potent cyclin-dependent kinase inhibitor, Mol. Cancer Ther. 9 (2010) 2344-2353.

[17] S. Lapenna, A. Giordano, Cell cycle kinases as therapeutic targets for cancer, Nat. Rev. Drug Discov. 8 (2009) 547-566.

[18] A. Goga, D. Yang, A.D. Tward, D.O. Morgan, J.M. Bishop, Inhibition of CDK1 as a potential therapy for tumors over-expressing MYC,, Nat. Med. 13 (2007) $820-827$.

[19] I. Androic, A. Krämer, R. Yan, F. Rödel, R. Gätje, M. Kaufmann, K. Strebhardt, J. Yuan, Targeting cyclin B1 inhibits proliferation and sensitizes breast cancer cells to taxol, BMC Cancer 8 (2008) 391-401.

[20] M.A. Dickson, G.K. Schwartz, Development of cell-cycle inhibitors for cancer therapy, Curr. Oncol. 16 (2009) 36-43.

[21] J.R. Dimmock, D.W. Elias, M.A. Beazely, N.M. Kandepu, Bioactivities of chalcones, Curr. Med. Chem. 6 (1999) 1125-1149.

[22] S.P. Bahekar, S.V. Hande, N.R. Agrawal, H.S. Chandak, P.S. Bhoj, K. Goswami, M.V.R. Reddy, Sulfonamide chalcones: synthesis and in vitro exploration for therapeutic potential against Brugia malayi, Eur. J. Med. Chem. 124 (2016) 262-269.

[23] P. Singh, A. Anand, V. Kumar, Recent developments in biological activities of chalcones: a mini review, Eur. J. Med. Chem. 85 (2014) 758-777.

[24] S. Kraege, K. Stefan, K. Juvale, T. Ross, T. Willmes, M. Wiese, The combination of quinazoline and chalcone moieties leads to novel potent heterodimeric modulators of breast cancer resistance protein (BCRP/ABCG2), Eur. J. Med. Chem. 117 (2016) 212-229.
[25] H. Mirzaei, S. Emami, Recent advances of cytotoxic chalconoids targeting tubulin polymerization: synthesis and biological activity, Eur. J. Med. Chem. 121 (2016) 610-639.

[26] S.M. Riyadh, T.A. Farghaly, M.A. Abdallah, M.M. Abdalla, M.R. Abd El-Aziz, New pyrazoles incorporating pyrazolylpyrazole moiety: synthesis, anti-HCV and antitumor activity, Eur. J. Med. Chem. 45 (2010) 1042-1050.

[27] M. Anzaldi, M. Chiara, M. Mazzei, M. Bertolotto, L. Ottonello, F. Dallegri, A. Balbi, Antiproliferative and proapoptotic activities of a new class of pyrazole derivatives in HL-60 cells, Chem. Biodivers. 6 (2009) 1674-1687.

[28] A. El-Shafei, A.A. Fadda, A.M. Khalil, T.A.E. Ameen, F.A. Badria, Synthesis antitumor evaluation, molecular modeling and quantitative structure-activity relationship (QSAR) of some novel arylazopyrazolodiazine and triazine analogs, Bioorg. Med. Chem. 17 (2009) 5096-5105.

[29] L.-W. Zheng, Y. Li, D. Ge, B.-X. Zhao, Y.-R. Liu, H.-S. Lv, J. Ding, J.-Y. Miao Synthesis of novel oxime-containing pyrazole derivatives and discovery of regulators for apoptosis and autophagy in A549 lung cancer cells, Bioorg. Med. Chem. Lett. 20 (2010) 4766-4770.

[30] Y.-S. Xie, H.-L. Zhao, H. Su, B.-X. Zhao, J.-T. Liu, J.-K. Li, H.-S. Lv, B.-S. Wang, D.S. Shin, J.-Y. Miao, Synthesis, single-crystal characterization and preliminary biological evaluation of novel ferrocenyl pyrazolo[1,5-a]pyrazin-4(5H)-one derivatives, Eur. J. Med. Chem. 45 (2010) 210-218.

[31] S. Lian, H. Su, B.-X. Zhao, W.-Y. Liu, L.-W. Zheng, J.-Y. Miao, Synthesis and discovery of pyrazole-5-carbohydrazide $\mathrm{N}$-glycosides as inducer of autophagy in A549 lung cancer cells, Bioorg. Med.Chem. 17 (2009) 7085-7092.

[32] G. Daidone, B. Maggio, D. Raffa, S. Plescia, D. Schillaci, M.V. Raimondi, Synthesis and in vitro antileukemic activity of new 4-triazenopyrazole derivatives, Il Farm. 59 (2004) 413-417.

[33] L.-C. Chou, L.-J. Huang, J.-S. Yang, F.-Y. Lee, C.-M. Teng, S.-C. Kuo, Synthesis of furopyrazole analogs of 1-benzyl-3-(5-hydroxymethyl-2-furyl)indazole (YC1) as novel anti-leukemia agents, Bioorg. Med. Chem. 15 (2007) 1732-1740.

[34] C.G. Tron, T. Pirali, G. Sorba, F. Pagliai, S. Busacca, A.A. Genazzani, Medicinal chemistry of combretastatin A4 present and future directions, J. Med. Chem. 49 (2006) 3033-3044.

[35] Y. Xia, Z.-W. Dong, B.-X. Zhao, X. Ge, N. Meng, D.-S. Shin, J-Y. Miao, Synthesis and structure-activity relationships of novel 1-arylmethyl-3-aryl-1H-pyrazole-5-carbohydrazide derivatives as potential agents against A549 lung cancer cells, Bioorg. Med. Chem. 15 (2007) 6893-6899.

[36] S. Schenone, O. Bruno, A. Ranise, F. Bondavalli, C. Brullo, P. Fossa, L. Mosti, G. Menozzi, F. Carraro, A. Naldini, C. Bernini, F. Manettic, M. Botta, New pyrazolo[3,4-d]pyrimidines endowed with A431 antiproliferative activity and inhibitory properties of Src phosphorylation, Bioorg. Med. Chem. Lett. 14 (2004) 2511-2517.

[37] R. Lin, G. Chiu, Y. Yu, P.J. Connolly, S. Li, Y. Lu, M. Adams, A.R. Fuentes-Pesquera, S.L. Emanuel, L.M. Greenberger, Design, synthesis, and evaluation of 3,4-disubstituted pyrazole analogues as anti-tumor CDK inhibitors, Bioorg. Med. Chem. Lett. 17 (2007) 4557-4561.

[38] S. Huang, R. Lin, Y. Yu, Y. Lu, P.J. Connolly, G. Chiu, S. Li, S.L. Emanuel, S.A. Middleton, Synthesis of 3-(1H-benzimidazol-2-yl)-5-isoquinolin-4ylpyrazolo[1,2-b]pyridine, a potent cyclin dependent kinase 1 (CDK1) inhibitor, Bioorg. Med. Chem. Lett. 17 (2007) 1243-1245.

[39] V.G. Reddy, T.S. Reddy, V.L. Nayak, B. Prasad, A.P. Reddy, A. Ravikumar, S. Taj, A. Kamal, Design, synthesis and biological evaluation of $\mathrm{N}-((1$-benzyl- $1 \mathrm{H}-$ 1,2,3-triazol-4-yl)methyl)-1,3-diphenyl-1H-pyrazole-4-carboxamides as CDK1/Cdc2 inhibitors, Eur. J. Med. Chem. 122 (2016) 164-177.

[40] N. Inceler, A. Yllmaz, S.N. Baytas, Synthesis of ester and amide derivatives of 1 phenyl-3-(thiophen-3-yl)-1H-pyrazole-4-carboxylic acid and study of their anticancer activity, Med. Chem. Res. 22 (2013) 3109-3118.

[41] S.N. Baytas, N. Inceler, A. Yllmaz, Synthesis, cytotoxicity and molecular properties prediction of novel 1,3-diarylpyrazole derivatives, Med. Chem. Res. 22 (2013) 4893-4908.

[42] S. Ducki, R. Forrest, J.A. Hadfield, A. Kendall, N.J. Lawrence, A.T. McGown, D. Rennison, Potent antimitotic and cell growth inhibitory properties of substituted chalcones, Bioorg. Med. Chem. Lett. 8 (1998) 1051-1056.

[43] S. Ducki, D. Rennison, M. Woo, A. Kendalla, J.F.D. Chabert, A.T. McGown, N.J. Lawrence, Combretastatin-like chalcones as inhibitors of microtubule polymerization. Part 1: synthesis and biological evaluation of antivascular activity, Bioorg. Med. Chem. 17 (2009) 7698-7710.

[44] S. Ducki, G. Mackenzie, B. Greedy, S. Armitage, J.F.D. Chabert, E. Bennett, J. Nettles, J.P. Snyder, N.J. Lawrence, Combretastatin-like chalcones as inhibitors of microtubule polymerisation. Part 2: structure-based discovery of alpha-aryl chalcones, Bioorg. Med. Chem. 17 (2009) 7711-7722.

[45] Real-Time and Dynamic Monitoring of Cell Proliferation and Viability for Adherent Cells, in, ACEA Biosciences, 2013.

[46] I. Durmaz, E.B. Guven, T. Ersahin, M. Ozturk, I. Calis, R. Cetin-Atalay, Liver cancer cells are sensitive to Lanatoside $C$ induced cell death independent of their PTEN status, Phytomedicine 23 (2016) 42-51.

[47] M.K. Bratenko, V.A. Chornous, M.V. Vovk, 4-functionally substituted 3 heterylpyrazoles IV. 1-phenyl-3-aryl(heteryl)-5-(4-pyrazolyl)-2-pyrazolines, Russ. J. Org. Chem. 37 (2001) 556-559. 